\title{
Crisis, educación y precariedad-afluencia. El rol de la educación en las condiciones de vida de la población española
}

\author{
Ramón Llopis Goig \\ Universitat de València (UV) \\ ramon.1lopis@uv.es \\ Benjamín TEJERINA \\ Universidad del País Vasco - Euskal Herriko Unibertsitatea (UPV/EHU) \\ b.tejerina@ehu.eus
}

Recibido: 09-06-2015

Aceptado: 08-02-2016

\section{Resumen}

El objeto de este artículo es estudiar la influencia del nivel educativo (capital cultural) en los procesos de precariedad-afluencia de la población española entre los años posteriores a la crisis de inicio de la década de 1990 y los años más duros de la crisis de 2007. A partir de los datos de las encuestas PHOGUE y ECV del Instituto Nacional de Estadística (INE) se han construido cuatro indicadores para medir la precariedad laboral, de ingresos, de salud y de vivienda y su distribución según distintas variables demográficas. Se pretende contrastar la hipótesis de que más educación significa más protección frente a la precariedad, estudiando diferentes condiciones de las condiciones de vida y existencia en momentos tanto de crecimiento como de crisis económica. Mediante un análisis multivariable se intenta determinar el nivel de impacto del capital cultural, alcance, evolución y, sobre todo, si sus efectos positivos o negativos están en proceso de expansión o desaceleración. El resultado tiene una doble aportación: de un lado, metodológica, consistente en la construcción de los indicadores; de otro lado, los resultados, con los que se puede reevaluar algunas generalizaciones sobre la pérdida de importancia del rol de la educación en las sociedades contemporáneas.

Palabras clave: educación; crisis económica; condiciones de vida; precariedad.

\section{Crisis, education and precariousness-affluence. The role of education in the Spanish living conditions}

\begin{abstract}
The purpose of this article is to study the influence of education achievement (cultural capital) in the processes of precariousness-affluent of Spanish population from the years after the crisis of 1990 to the beginning of the hardest years of the current crisis. From the ECHP (European Community Household Panel) data and the SILC (Living Conditions Survey) of Instituto Nacional de Estadística (INE) four indicators are built to measure the evolution of job labour, income, health and housing and their distribution according to different demographic variables. Studying different living conditions in times of growth and economic crisis it is intended to test the hypothesis that more education means more protection. By the use of multivariate analysis we attempt to determine the level of impact of cultural capital, its scope, its evolutionary dynamics and, above all, whether positive or negative effects are being expanded or deceleration. The result is a double contribution: on the methodological side consisting of the construction of the indicators; on the other hand, the results, with whom it is possible to question some generalizations
\end{abstract}


about the role of education in contemporary societies.

Key words: education; economic crisis; living conditions; precariousness.

\section{Referencia normalizada}

Llopis Goig R. y B. Tejerina (2016): “Crisis, educación y precariedad-aluencia”, Política y Sociedad, 53 (2), pp. 413-442.

Sumario: Introducción. 1. Método. 2. Resultados. 3. Análisis multivariable: educación e indicadores de precariedad. 4. Discusión. 5. Bibliografía.

\section{Introducción ${ }^{1}$}

La educación está bajo el velo de la sospecha. La educación se encuentra entre el fuego cruzado de las críticas que recibe desde sectores neoliberales de la sociedad por su falta de eficacia en relación con el excesivo gasto y el intento sistemático de moldearlo a imagen y semejanza de los principios ideológicos de la organización política que gobierna. El debate científico también se contamina, en ocasiones, de una precipitada deliberación al hilo de reformas improvisadas o carentes de una concienzuda evaluación. El aumento del interés por la educación es coherente con la creciente centralidad que el capital educativo ha adquirido en las últimas décadas. Mientras las instituciones universitarias viven una encarnizada lucha por posicionarse lo más alto posible en los distintos rankings clasificatorios existentes, con el ánimo de atraer más estudiantes y recursos, cada vez más personas llegan y terminan sus estudios obligatorios, ampliando su formación con especialidades universitarias y cursos de posgrado, lo que produce una cierta inflación de títulos y una relativa devaluación de las oportunidades y prestigio asociado a dichos estudios respecto a los tiempos en que su logro era menos frecuente.

Lo que nos interesa de este debate multifacético es la pregunta por el valor de los estudios: ¿qué valor podemos atribuir al capital educativo en la sociedad española actual? Prácticamente todas las instituciones nacionales e internacionales, así como numerosas investigaciones señalan su importancia, y no es nuestra intención cuestionar esta evidencia social. De hecho, numerosos inversores destinan sus recursos a la implantación de nuevas universidades, mientras un número importante de estudiantes abandona las aulas universitarias con cierta frustración y con la convicción de que su esfuerzo no está dando los frutos esperados.

No es necesario reseñar aquí todos los trabajos que ponen de manifiesto esta dialéctica, de un lado y de otro. Desde nuestra perspectiva es posible encontrar

${ }^{1}$ Este artículo ha contado con la financiación del Ministerio de Economía y Competitividad a través del proyecto de investigación CSO2011-23252 "Respuestas sociales a la crisis y procesos de precarización de la vida en la sociedad contemporánea: Bélgica, España, Francia, Italia y Portugal”, así como del Grupo de investigación consolidado IT706-13 del Sistema Universitario Vasco. 
argumentos convincentes en ambos lados, aunque la forma en que se aborda aquí el problema es algo diferente. El objetivo es conocer hasta qué punto el capital educativo ${ }^{2}$ es posibilitador de afluencia y protector contra la precariedad. Hoy se habla tanto de sociedad precaria y del precariado como una nueva clase social (Standing, 2011) que se ha convertido en un lugar común.

Para los fines de este artículo, la precariedad vital puede definirse como aquella situación de origen estructural o temporal caracterizada por una restricción, imposibilidad o limitación de acceso a las condiciones, requisitos y recursos considerados necesarios para poder definir, llevar a cabo y gestionar una vida autónoma. La afluencia se caracterizaría por una ausencia de restricción o limitación. El nivel de restricción o limitación puede alcanzar diferentes grados de intensidad en relación con los recursos medios disponibles en una sociedad determinada. La precariedad y la afluencia son, pues, categorías relacionales en un doble sentido: a) en relación con la media de la sociedad, grupo o categoría social de que se trate; y b) en relación con los diversos ámbitos existenciales. El binomio precariedad/afluencia es susceptible de medición y cuantificación a partir de diferentes indicadores como señalaremos más adelante en el apartado 2.

La precariedad/afluencia es un concepto que aúna la condición y la situación personal en la relación del individuo con el medio. Es una forma de definir la relación del individuo con el medio social. En la precarización como proceso también participan las instituciones por medio de las propias prácticas de la acción pública o por la ausencia de ésta. Además, las instituciones normativizan la precariedad en la medida en que enseñan a los individuos a moverse en ella.

El concepto de precariedad se ha venido utilizando, en los últimos años, asociado, fundamentalmente, con la esfera económica y al mundo laboral. Se ha hablado de trabajadores flexibles y precarios (Castillo, 1995; La Roca y Sánchez, 1996; Bilbao, 1998 y 1999; Carnoy, 2001; Díaz-Salazar, 2003; Arriola y Vasapollo, 2005; Zubero, 2006), precariedad laboral (Bilbao, Cano y Standing, 2000) así también como de empleo precario (Moreno Fernández, 2000; Paugam, 2000; Mur y Petit, 2003; Polavieja, 2003; Barbier, 2005; Cingolani, 2005; Frade y Darmon, 2005; Laparra, 2007).

Determinados colectivos han atraído en mayor grado la atención de los investigadores: jóvenes, mujeres, desempleados, empleados temporales e inestables, e inmigrantes, fundamentalmente. El análisis de las condiciones de acceso al empleo por parte de los jóvenes ha tenido un importante desarrollo como: freno a su emancipación (Casal, 1996; Rodríguez, 1999; Hernández, 2002; Santos, 2003; Jurado, 2007), el empleo de jóvenes con recursos limitados (Machado, 2007), jóvenes que trabajan con el intelecto (Rambach y Rambach, 2001), su repercusión en el proceso de construcción de su identidad (Sánchez Moreno, 2004; Alteri y Raffini, 2007; Díaz Moreno, 2007; Sánchez Moreno y Barrón, 2007), la inserción sociolaboral (Pérez-Agote, Tejerina

\footnotetext{
${ }^{2}$ Aunque el concepto de capital educativo y capital cultural puede tener distintas acepciones y significados, dependiendo de la finalidad que enmarca distintos estudios, para los fines de este trabajo se utilizarán como sinónimos, y más específicamente como equivalentes a nivel de educación formal alcanzado.
} 
y Santamaría, 2001; Cal Barredo, 2002; Casal, García, Merino y Quesada, 2006), la influencia en el voto juvenil (Lago, 2007; Salido y Martín, 2007), la cultura de la precariedad y el cambio generacional (Gálvez, 2005 y 2007). Desde una perspectiva de género hay que considerar, por un lado, los estudios relativos al propio colectivo de mujeres y, por el otro, a la familia como institución social. En el primer ámbito hay que destacar la reflexión sobre género (VV.AA., 2003; Carrasquer y Torns, 2007); jóvenes madres solteras (González, Jimenez y Morgado, 2004); trabajo informal y trabajo doméstico (Banyuls, Cano, Picher y Sánchez, 2003); efectos sobre las estrategias de vida (Prieto, 2007); compatibilización/conciliación de la vida laboral y familiar (San José, 2004; Tobío, 2005); precariedad familiar (Morente y Barroso, 2003) y en las familias monoparentales (Moreno, 2000).

La inmigración y su proceso de inserción en la economía española ha ocupado buena parte de la investigación empírica sobre este fenómeno (Blanco, 1995; Colectivo IOE, 1999 y 2001). Otras investigaciones se han centrado en las condiciones laborales de los inmigrantes que se han incorporado al mercado de trabajo español, en muchos casos de manera informal (Martínez Veiga, 1997 y 1999), en las estrategias de inclusión de inmigrantes (Ramirez, 1996), los procesos de precarización y exclusión social (Rojo Torrecilla, 2002), las relaciones entre marco legal, mercado de trabajo y discriminación (Cachón, 2009; Aysa-Lastra y Cachón, 2013) y la precariedad residencial (García, 2006; Carbajo, 2014 y 2015). El concepto de precariedad ha adquierido en muchos de estas investigaciones nuevas acepciones a la presentada anteriormente, aunque no podemos detenernos en ello ahora ${ }^{3}$.

Sin embargo, pocos avances se han producido en el ámbito de los análisis sistemáticos de la relación entre capital educativo y precariedad vital en la sociedad española contemporánea. En esta paradójica ausencia queremos centrar este artículo. Paradójica, porque a pesar de que muchos de los anteriores estudios mencionados señalan, apuntan o insinúan la relevancia de dicho capital casi nunca se ha explorado de manera sistemática su influencia. El objetivo principal de este artículo consiste en evaluar el rol que ha desempeñado el capital educativo en relación con los niveles de precarización y afluencia de la población española en las dos últimas décadas. El artículo pretende contribuir a mejorar nuestro conocimiento sobre varios aspectos: a) la ausencia de estudios sistemáticos sobre la relación entre el capital educativo de la población española y la afluencia-precariedad vital; b) la atención a diversas dimensiones de la vida como la salud y la vivienda, además de la actividad laboral y los ingresos; c) la consideración de un período de tiempo lo suficientemente amplio como para ver tendencias en momentos de crecimiento económico y los efectos de períodos de crisis; y d) la comparación y medición cuantitativa de la relación entre las condiciones de vida (de más precariedad a más afluencia) y los distintos niveles de capital educativo alcanzado, con una valoración específica de la enseñanza superior en un contexto de creciente cuestionamiento de la misma.

${ }^{3}$ Para desarrollos distintos sobre el concepto de precariedad puede consultarse (Tejerina, Cavia, Santamaría y Carbajo, 2012:24; Cavia y Martínez, 2013; Fortino, Tejerina, Cavia y Calderón, 2012). 
Para abordar estos objetivos presentamos nuestra argumentación en cuatro apartados. En primer lugar, se presentan las definiciones operativas, las fuentes de datos y las características de los instrumentos de medida construidos para esta investigación. En segundo lugar, se analiza la situación y evolución del nivel educativo de la población española entre 1995 y 2013, deteniéndonos en el análisis de la relación con la edad, la situación laboral y la ocupación. En tercer lugar, se profundiza en la relación entre los estudios y los índices de precariedad laboral, de ingresos, de salud y de vivienda. En cuarto lugar, se interpretan los análisis de regresión calculados para los cuatro indicadores de precariedad (laboral, de ingresos, de salud y de vivienda) entre 1995 y 2013 y se examina la influencia que sobre los mismos tienen diversas variables sociodemográficas.

\section{Método}

El análisis que se presenta en este artículo se basa en las ediciones de 2005, 2010 y 2013 de la Encuesta de Condiciones de Vida del Instituto Nacional de Estadística (ECV-INE), aunque para disponer de una serie más amplia se ha recurrido también a dos encuestas anteriores, las de 1995 y 2000, ambas del Panel de Hogares de la Unión Europea (PHOGUE). La Encuesta de Condiciones de Vida (ECV) es una encuesta dirigida a hogares que proporciona información estadística sobre la composición y distribución de la renta y sobre las condiciones de vida de la población. Pertenece al conjunto de estadísticas europeas armonizadas, por tanto, cuenta con una metodología y operacionalización de conceptos común a todos los países miembros de la Unión Europea. Es sucesora del Panel de Hogares Europeo (PHOGUE) con el que comparte algunos objetivos referidos a la renta y las condiciones de vida. Las diferencias metodológicas entre ambas encuestas son el mayor tamaño muestral de la primera y el hecho de que mientras la segunda era un panel puro (la muestra inicial se mantuvo permanente en las sucesivas ediciones) la ECV es un panel rotante, por lo que tiene un componente transversal y otro longitudinal, si bien se le da prioridad al primero en lo que respecta a la puntualidad y la comparabilidad ${ }^{4}$.

Debe tenerse también en cuenta que los años mencionados se refieren a la fecha de realización del trabajo de campo de la encuesta - no al periodo al que se circunscribe la información económica recabada- por lo que los tres primeros cortes temporales coinciden con un periodo de crecimiento de la economía española, el cuarto sólo cubre el primer año de la crisis y el quinto recoge una parte de sus efectos sobre las condiciones de vida de la población española.

Como ya se ha señalado, en la primera sección del apartado de resultados se presenta un análisis de la evolución de la educación en España. En la segunda y tercera sección se realizan diversos análisis bivariables y multivariables en los que se ha tomado como

\footnotetext{
${ }^{4}$ Más información sobre las características de la Encuesta de Condiciones de Vida (ECV) así como sobre los cambios que supuso su adopción en todos los países de la UE entre 2003 y 2004 puede encontrarse en la documentación hecha pública por el Instituto Nacional de Estadística en su página web (INE, 2005).
} 
variables dependientes cuatro indicadores de precariedad construidos específicamente para este trabajo. Se trata de los indicadores de precariedad de ingresos, precariedad laboral, precariedad de salud y precariedad de vivienda.

Por lo que se refiere al proceso de estandarización y homogeneización de los ficheros de microdatos se procedió, en primer lugar, a la fusión de los casos y las variables de las personas y los hogares contenidos en cada uno de los ficheros proporcionados por el INE, una vez que habían sido convertidos en formato sav y etiquetados. A continuación, se fusionó, por un lado, los ficheros que correspondían a PHOGUE y, por otro, los de ECV. En tercer lugar, para la obtención de un único fichero se homogeneizaron las variables de ambos ficheros, asignando denominaciones comunes y ajustando los valores al denominador de PHOGUE. En este proceso se calcularon los coeficientes de ponderación para individuos y para hogares para la ECV a partir de los factores de elevación facilitados por el INE, puesto que en el caso de PHOGHE se encuentran ya calculados. La variable nivel de estudios se homogeneizó a partir del sistema de codificación de PHOGHE, mientras que en el caso de la variable ingresos los valores de PHOGUE fueron trasladados de pesetas a euros. En cuarto y último lugar, una vez realizadas todas las transformaciones y recodificaciones mencionadas se procedió a la fusión final de los ficheros con las encuestas PHOGHE y ECV obteniéndose de ese modo una única matriz de datos con la que se han realizado los cálculos de la investigación que se presenta en este trabajo.

Por lo que se refiere al cálculo de los indicadores, para la elaboración del indicador de precariedad laboral se han introducido las variables de situación laboral, ocupación, clase social (situación profesional) y tipo de contrato. Se han escalado los niveles de la variable situación laboral de menor a mayor precariedad siguiendo el siguiente orden: trabajo a tiempo completo, trabajo a tiempo parcial, parado y otras situaciones relacionadas con la inactividad. Respecto a la variable ocupación, los parados han sido incluidos en la categoría de asalariados y se ha mantenido agrupados a los inactivos. Por último, por lo que se refiere al tipo de contrato, los empresarios o autónomos han sido incluidos en el nivel de mínima precariedad y se ha generado una categoría para los sin contrato. Este procedimiento ha impedido la pérdida de un importante número de casos, y ha hecho posible la obtención de un gradiente de precariedad laboral. Una vez recodificadas estas variables, se efectuó un análisis factorial de componentes principales (por tratarse de variables ordinales), del que se obtuvieron los pesos para calcular un indicador de precariedad laboral posteriormente estandarizado en un rango de cero a diez.

Para la elaboración del indicador de precariedad de ingresos se asumió como ingresos totales los del hogar, es decir, la renta disponible del hogar, repartida entre todos sus miembros. Se deflactó en euros corrientes (de cada año) y se obtuvieron euros constantes (en su valor de 2009) con la finalidad de obtener cantidades de moneda comparables en términos de capacidad de compra ${ }^{5}$. Se mantuvieron las variables por

${ }^{5}$ Para ello se obtuvieron los datos correspondientes del Banco de España de la serie del IPC y se tomaron los interanuales de junio a junio para los años 2004 (encuesta de 2005), 2009 (encuesta de 2010) y 2012 (encuesta de 2013). 
tipo de ingreso - rentas del trabajo, rentas del capital, prestaciones por desempleo, por jubilación...- y las intermedias agregadas (una vez deflactadas), de rentas -suma de rentas del trabajo y del capital- y ayudas sociales -suma de las individuales y las del hogar per cápita-. También se incluyeron estas dos últimas variables en una variable de ingresos totales (suma de rentas y de ayudas). Se ha calculado el indicador de precariedad de ingresos a partir de la renta disponible del hogar per cápita, lo que proporciona un indicador de precariedad de ingresos cercano a las condiciones de vida del individuo como miembro del hogar del que forma parte ${ }^{6}$. Se generó una variable para la renta disponible del hogar per cápita con siete intervalos, calculados a partir de la mitad de la desviación media. Para calcular el indicador de precariedad de ingresos se obtuvo una variable de doscientos intervalos, con el fin de corregir los casos extremos y mantener una varianza amplia. Finalmente, con estos doscientos intervalos se calculó un índice de cero a diez que posteriormente fue invertido para lograr que las puntuaciones más elevadas se refirieran a los mayores niveles de precariedad de ingresos.

En el cálculo del indicador de precariedad de salud se han incluido variables relacionadas con el estado de salud, la prevalencia de alguna enfermedad crónica o la incapacidad y el carácter limitante de enfermedades o incapacidades. Una vez recodificadas estas variables, asignando los valores altos a las posiciones relacionadas con un peor estado de salud, se realizó un análisis factorial de componentes principales. La varianza explicada conjuntamente y las saturaciones han resultado ser tan elevadas que se ha usado el propio factor obtenido como indicador de precariedad de salud, aunque para adoptar la misma unidad de medida que en el resto de indicadores de precariedad, fue escalado a un intervalo de cero a diez.

Por último, para la obtención del indicador de precariedad residencial se ha recurrido, por un lado, a las variables relativas al régimen de adquisición y a la tenencia o no de una hipoteca y, por otro lado, a las condiciones y equipamiento de la vivienda y el entorno próximo. El régimen de adquisición y la tenencia de una hipoteca se han agrupado en una única variable (propiedad, cesión gratuita, vivienda hipotecada y alquiler). Se ha reordenado para que los valores más elevados correspondan a las situaciones más problemáticas. Respecto al equipamiento, sólo se han contabilizado como precarias aquellas situaciones en que se afirmaba la no posesión y la imposibilidad de permitírselo. Las variables creadas fueron: condiciones de la vivienda, falta de equipamiento y problemas de entorno, las tres métricas dado que el valor contabilizado indicaba el número real de problemas o carencias de la vivienda. Se realizó un análisis factorial de componentes principales con las tres variables relativas a las condiciones de

${ }^{6}$ Somos conscientes de que esta atribución puede ser problemática en términos generales y en casos particulares. Existe una amplia discusión y un buen cuerpo de investigaciones empíricas que ponen de manifiesto que no tener en cuenta diferencias de edad y, sobre todo, de género introduce considerables distorsiones entre la situación que esta forma de operar presenta y lo que sucede en la realidad. Especialmente relevante resulta tener en cuenta cómo y quién toma las decisiones sobre la distribución de los ingresos y la ejecución del gasto. Sin embargo, para los fines de este artículo consideramos que esta forma de proceder se adecúa a sus objetivos, dejando para más adelante la posibilidad de profundizar en estas otras dimensiones. 
la vivienda, más la que agregaba el régimen de adquisición con la tenencia de hipoteca. Los pesos obtenidos se usaron para crear el indicador de precariedad residencial o de la vivienda.

\section{Resultados}

\subsection{Evolución de los niveles de educación en España}

A comienzos del siglo XX, en la universidad española apenas se hallaban matriculadas quince mil personas. Hacia mediados de siglo se alcanzó la cifra de cincuenta mil; y a finales de la década de 1960, si se incorpora la matrícula de las carreras técnicas básicas, se sobrepasaba el umbral de doscientos mil estudiantes. Desde ese momento, tanto la matrícula en facultades como en los diversos tipos de escuelas que comenzaron a proliferar, permitió dar un salto espectacular, de manera que en treinta años se llegó a alcanzar una matrícula superior al millón y medio (Ariño et al., 2008: 3235). Sin embargo, desde el curso 1999-2000 -año en que se alcanza el nivel máximo de matriculación-, se ha producido un descenso del número total de estudiantes universitario, muy relacionado con la reducción de la natalidad de las últimas décadas. Esta tendencia ha vuelto a invertirse en el curso 2008-2009, ya que la matrícula ha crecido en los últimos cursos. En el conjunto del período, la universidad española ha atravesado dos etapas muy claras, que en terminología de Trow podría definirse como una primera de elites a una segunda de masas ${ }^{7}$.

Como recoge la Tabla 1, las personas sin estudios tienen una presencia cada vez mayor a medida que aumenta la edad, tendencia que aumenta con el paso del tiempo. Su presencia se va reduciendo a medida que se desciende en los grupos de edad. La misma tendencia se aprecia entre las personas con estudios primarios. Por otro lado, 6 de cada diez $(62,7 \%)$ de los que habían cursado estudios secundarios obligatorios en 1995 tenían entre 16 y 34 años, y se había reducido 18 años después al 30,8\%. En 1995, entre los que tenían 16 y 34 años había alcanzado el nivel de estudios secundarios posobligatorios el $70,2 \%$, reduciéndose al $37,4 \%$ en el año 2013. Por último, los universitarios entre 16 y 34 años, que eran el 43,3\% en 1995, disminuyen hasta el 30,5\% en 2013. Lo que podría significar una tendencia a la estabilización, primero, y a la disminución, después, del porcentaje de universitarios, no es sino efecto de la disminución del peso del grupo de edad más joven en el conjunto de la población como consecuencia de la reducción de sus efectivos por el descenso demográfico. El efecto del avance de la educación supone que las personas que no tienen estudios o tienen estudios primarios se sitúan en los grupos de mayor edad. Quienes tienen estudios secundarios o secundarios obligatorios

${ }^{7}$ Martin Trow (1972) distingue tres grandes etapas en la historia de la Universidad: de elite, de masa y universal. Para Trow, una universidad es de elite cuando participa en ella menos del quince por ciento de una clase de edad. Se da el salto a la universidad de masa cuando la participación de las cohortes de edad de referencia se sitúa entre el quince y el cuarenta por ciento. Y cuando se supera esa cifra se entra en la vía del servicio universal (véase Romainville, 2004: 130). 
aumentan en las edades intermedias (35-54 años), y el porcentaje de universitarios calculado sobre su cohorte aumenta en todas las edades.

Tabla 1: Nivel de estudios y edad en España de 1995 a 2013

\begin{tabular}{|c|c|c|c|c|c|c|}
\hline $\begin{array}{l}\text { Nivel } \\
\text { de estudios }\end{array}$ & Edad & 1995 & 2000 & 2005 & 2010 & 2013 \\
\hline \multirow{3}{*}{ Sin estudios } & 16-34 años & 4,0 & 3,5 & 5,6 & 4,6 & 6,5 \\
\hline & 35-54 años & 19,2 & 15,2 & 9,3 & 9,9 & 12,4 \\
\hline & 55 y más años & 76,8 & 81,3 & 85,1 & 85,5 & 81,1 \\
\hline \multirow{3}{*}{ Primaria } & 16-34 años & 15,9 & 10,9 & 12,8 & 10,4 & 9,6 \\
\hline & 35-54 años & 40,4 & 36,1 & 27,8 & 21,5 & 19,5 \\
\hline & 55 y más años & 43,7 & 53,0 & 59,4 & 68,1 & 70,9 \\
\hline \multirow{3}{*}{$\begin{array}{l}\text { Secundaria } \\
\text { obligatoria }\end{array}$} & 16-34 años & 62,7 & 55,0 & 41,8 & 36,4 & 30,8 \\
\hline & 35-54 años & 28,7 & 36,1 & 42,1 & 42,8 & 45,2 \\
\hline & 55 y más años & 8,6 & 8,9 & 16,1 & 20,8 & 24,1 \\
\hline \multirow{3}{*}{$\begin{array}{l}\text { Secundaria } \\
\text { postobligatoria }\end{array}$} & 16-34 años & 70,2 & 62,5 & 50,3 & 41,7 & 37,4 \\
\hline & 35-54 años & 23,8 & 30,1 & 37,8 & 43,1 & 43,7 \\
\hline & 55 y más años & 6,0 & 7,4 & 11,9 & 15,2 & 18,9 \\
\hline \multirow{3}{*}{ Superiores } & 16-34 años & 43,3 & 51,1 & 46,4 & 37,1 & 30,5 \\
\hline & 35-54 años & 42,1 & 33,9 & 39,8 & 47,0 & 49,5 \\
\hline & 55 y más años & 14,6 & 15,0 & 13,8 & 15,9 & 20,0 \\
\hline
\end{tabular}

Fuente: Elaboración propia a partir de ECV (2005, 2010 y 2013) y PHOGUE (1995 y 2000).

La mayor parte de las personas sin estudios sigue siendo casada (53,2\% en 2013). Sin embargo, dentro de este grupo aumenta progresivamente la presencia de las personas viudas $(32,1 \%)$. La misma tendencia se registra en el caso de las personas con estudios primarios, aunque con porcentajes distintos, pues en este caso las personas casadas son el 59,3\% y las viudas el 19\%. En todos los demás niveles educativos las personas casadas constituyen el grupo mayoritario $(54,1 \%$ entre las personas con estudios de secundaria obligatoria, $49,8 \%$ secundaria postobligatoria y $55,4 \%$ en superiores), seguido del grupo de las solteras $(36,1 \%, 40,8 \%$ y $36,5 \%$ respectivamente). Una última 
variable que debe tenerse en cuenta al examinar la distribución del capital educativo tiene que ver con el aumento de la población inmigrante desde finales de la década de 1990. De representar un porcentaje muy bajo en 1995, la población de nacionalidad extranjera ha pasado a suponer entre un ocho y un nueve por ciento de la población con estudios primarios, secundarios o superiores en 2013. En 2013 la mayor presencia de personas de origen extranjero se daba entre las personas sin estudios $(11,4 \%)$ y con estudios de secundaria postobligatoria $(16,1 \%)$.

La Tabla 2 permite examinar la evolución entre 1995 y 2013 de la situación laboral de la población española según el nivel de estudios terminados. El 80\% de los que no tienen estudios se situaba en 1995 en posiciones de inactividad (jubilados, labores del hogar, otras inactividades) y en 2013 era el 84,4\%, lo que significa que estas posiciones tienden a situarse en la generación de los mayores. Los que tienen estudios primarios pierden peso como trabajadores a tiempo completo al pasar del $32 \%$ al $13,9 \%$, y aumentan también entre los parados y jubilados. El efecto en el desempleo como resultado de la crisis está relacionado con el nivel de estudios, ya que a mayor nivel de estudios menor incremento de la tasa de desempleo: con excepción de quienes tienen estudios primarios (6,6 puntos porcentuales más) se nota en mayor medida entre los que tienen estudios secundarios obligatorios ( 8 puntos) y también entre los que tienen secundarios posobligatorios (5,2 puntos), con un menor impacto entre los que tienen estudios superiores ( 4,2 puntos).

Tabla 2: Relación con la actividad según nivel de estudios de 1995 a 2013

\begin{tabular}{|l|l|r|r|r|r|r|}
\hline \multirow{4}{*}{ Nivel estudios } & Actividad & 1995 & 2000 & 2005 & 2010 & 2013 \\
\hline \multirow{5}{*}{ Sin estudios } & Trabajando a tiempo completo & 11,3 & 10,2 & 6,8 & 4,0 & 5,9 \\
\cline { 2 - 7 } & Trabajando a tiempo parcial & 1,8 & 0,8 & 1,4 & 1,2 & 1,1 \\
\cline { 2 - 7 } & Parado & 6,5 & 4,2 & 3,4 & 5,4 & 8,6 \\
\cline { 2 - 7 } & Estudiante & 0,1 & 0,1 & 0,3 & 0,4 & - \\
\cline { 2 - 7 } & Jubilado/retirado & 29,1 & 35,5 & 44,3 & 39,9 & 37,0 \\
\cline { 2 - 7 } & Labores del hogar & 33,2 & 33,9 & 30,3 & 32,4 & 32,7 \\
\cline { 2 - 7 } & Otra inactividad económica & 18,1 & 15,4 & 13,6 & 16,7 & 14,7 \\
\hline \multirow{5}{*}{ Primaria } & Trabajando a tiempo completo & 32,0 & 29,1 & 27,4 & 19,4 & 13,9 \\
\cline { 2 - 7 } & Trabajando a tiempo parcial & 2,3 & 2,7 & 3,3 & 3,3 & 2,9 \\
\cline { 2 - 7 } & Parado & 9,1 & 4,1 & 6,4 & 11,6 & 15,7 \\
\cline { 2 - 7 } & Estudiante & 0,6 & 3,2 & 1,4 & 2,2 & 2,7 \\
\cline { 2 - 7 } & Jubilado/retirado & 15,6 & 21,1 & 28,2 & 32,9 & 34,8 \\
\cline { 2 - 6 } & Labores del hogar & 30,7 & 31,6 & 26,1 & 24,3 & 22,9 \\
\cline { 2 - 6 } & Otra inactividad económica & 9,7 & 8,3 & 7,3 & 6,4 & 7,0 \\
\hline
\end{tabular}




\begin{tabular}{|c|c|c|c|c|c|c|}
\hline Nivel estudios & Actividad & 1995 & 2000 & 2005 & 2010 & 2013 \\
\hline \multirow{7}{*}{$\begin{array}{l}\text { Secundaria } \\
\text { obligatoria }\end{array}$} & Trabajando a tiempo completo & 43,7 & 50,4 & 50,3 & 41,8 & 34,0 \\
\hline & Trabajando a tiempo parcial & 3,4 & 3,6 & 5,6 & 6,1 & 7,5 \\
\hline & Parado & 17,5 & 10,3 & 9,9 & 19,0 & 25,5 \\
\hline & Estudiante & 9,4 & 12,1 & 9,1 & 9,5 & 8,8 \\
\hline & Jubilado/retirado & 3,2 & 2,3 & 5,4 & 8,1 & 9,2 \\
\hline & Labores del hogar & 18,0 & 18,4 & 15,7 & 11,2 & 10,2 \\
\hline & Otra inactividad económica & 4,8 & 2,9 & 3,9 & 4,3 & 4,9 \\
\hline \multirow{7}{*}{$\begin{array}{l}\text { Secundaria } \\
\text { post obligatoria }\end{array}$} & Trabajando a tiempo completo & 41,5 & 50,3 & 52,4 & 49,2 & 42,1 \\
\hline & Trabajando a tiempo parcial & 3,5 & 4,0 & 6,7 & 7,3 & 8,0 \\
\hline & Parado & 11,4 & 6,4 & 6,9 & 12,1 & 16,6 \\
\hline & Estudiante & 29,8 & 26,1 & 17,4 & 15,1 & 16,1 \\
\hline & Jubilado/retirado & 2,4 & 3,1 & 5,8 & 5,8 & 7,7 \\
\hline & Labores del hogar & 7,9 & 8,4 & 8,3 & 7,3 & 6,6 \\
\hline & Otra inactividad económica & 3,5 & 1,8 & 2,4 & 3,0 & 2,9 \\
\hline \multirow{7}{*}{ Superiores } & Trabajando a tiempo completo & 63,6 & 62,3 & 67,5 & 66,3 & 58,9 \\
\hline & Trabajando a tiempo parcial & 4,5 & 6,3 & 6,3 & 6,7 & 8,1 \\
\hline & Parado & 10,4 & 7,8 & 6,9 & 10,2 & 14,6 \\
\hline & Estudiante & 6,9 & 12,7 & 6,3 & 4,2 & 4,2 \\
\hline & Jubilado/retirado & 6,0 & 5,2 & 6,7 & 7,0 & 8,9 \\
\hline & Labores del hogar & 5,1 & 5,1 & 4,5 & 3,6 & 3,6 \\
\hline & Otra inactividad económica & 3,4 & 0,7 & 1,9 & 2,0 & 1,8 \\
\hline
\end{tabular}

Fuente: Elaboración propia a partir de ECV (2005, 2010 y 2013) y PHOGUE (1995 y 2000).

Las personas sin estudios pierden peso entre la población ocupada y lo ganan en la población inactiva: las personas sin estudios que estaban trabajando en 1995 eran el 13,1\%, mientras en 2013 se reducen hasta el 7\%. Por el contrario, los jubilados y retirados pasan del $29,1 \%$ al $37 \%$ en el mismo periodo. Algo similar, aunque con una tendencia más pronunciada, es lo que se produce en el caso de las personas con estudios primarios. Los que están trabajando ven reducida su presencia del $34,3 \%$ al $16,8 \%$, mientras que entre los jubilados y retirados se duplican pasando del $15,6 \%$ al $34,8 \%$, si bien en el caso de las dedicadas a las tareas del hogar descienden desde el 30,7\% hasta el 22,9\%. La situación laboral de las personas con estudios de secundaria obligatoria varía muy poco en el periodo de referencia. En 1995 estaba trabajando el 47,1\% y en 
2013 era el 47,9\%, si bien los jubilados y retirados han pasado del 3,2\% al 8,1\%. La mejora de la situación laboral ha sido clara en el caso de la población con estudios de secundaria postobligatoria que ha pasado del $45 \%$ al $50,1 \%$. Por último, entre la población con estudios superiores lo más destacable es la ligera reducción de los que se encuentran trabajando, que de ser el 68,1\% en 1995 han pasado a ser el 67\% en 2013.

Desde el punto de vista de la relación entre nivel educativo y la ocupación (Tabla 3) se observa que los que no tienen estudios o tienen estudios primarios aumentan su peso entre los trabajadores no cualificados; los agricultores y trabajadores agropecuarios cualificados se reducen en el nivel de estudios bajo y se mantienen en los elevados; los que tienen estudios secundarios posobligatorios reducen su presencia entre los profesionales, científicos e intelectuales, los técnicos y profesionales de nivel medio y aumentan ligeramente entre los empleados de oficina y, sobre todo, entre los trabajadores de servicios (que puede deberse a una pérdida de posición social o movilidad descendente, a un cambio generacional o a los cambios en la estructura ocupacional por sectores y ramas de actividad); los que tienen estudios superiores pierden peso entre los directores de empresa y administraciones públicas, también entre los profesionales, científicos e intelectuales, aumentando entre los trabajadores de servicios y empleados de oficina, así como entre los grupos ocupacionales de menor cualificación.

Tabla 3: Ocupación y nivel de estudios de 1995 a 2013

\begin{tabular}{|l|l|r|r|r|r|r|}
\hline Nivel estudios & Ocupación & 1995 & 2000 & 2005 & 2010 & 2013 \\
\hline \multirow{5}{*}{ Sin estudios } & $\begin{array}{l}\text { Dirección empresas y } \\
\text { administraciones públicas }\end{array}$ & 4,3 & 12,6 & 1,0 & 1,2 & 0,9 \\
\cline { 2 - 7 } $\begin{array}{l}\text { Profesionales, científicos e } \\
\text { intelectuales }\end{array}$ & 0,3 & -- & -- & - & - \\
\cline { 2 - 7 } & $\begin{array}{l}\text { Técnicos y profesionales de nivel } \\
\text { medio }\end{array}$ & 0,3 & 0,5 & 0,9 & 0,8 & 1,0 \\
\cline { 2 - 7 } & Empleados oficina & 0,8 & 1,9 & 0,6 & 0,4 & - \\
\cline { 2 - 7 } & Trabajadores servicios y vendedores & 9,5 & 4,3 & 7,3 & 6,0 & 6,8 \\
\cline { 2 - 7 } & $\begin{array}{l}\text { Agricultores y trabajadores agr. } \\
\text { cualificados }\end{array}$ & 21,1 & 19,8 & 18,5 & 13,4 & 13,9 \\
\cline { 2 - 7 } & Oficiales, operarios y artesanos & 18,6 & 20,3 & 17,3 & 15,9 & 19,1 \\
\cline { 2 - 7 } & Operadores de instalaciones & 6,8 & 8,2 & 5,2 & 8,4 & 5,8 \\
\cline { 2 - 7 } & Trabajadores no cualificados & 38,4 & 32,4 & 49,2 & 54,0 & 52,6 \\
\hline
\end{tabular}




\begin{tabular}{|c|c|c|c|c|c|c|}
\hline Nivel estudios & Ocupación & 1995 & 2000 & 2005 & 2010 & 2013 \\
\hline \multirow{9}{*}{ Primaria } & $\begin{array}{l}\text { Dirección empresas y } \\
\text { administraciones públicas }\end{array}$ & 7,9 & 11,5 & 3,5 & 5,4 & 1,4 \\
\hline & $\begin{array}{l}\text { Profesionales, científicos e } \\
\text { intelectuales }\end{array}$ & 0,1 & 0,2 & 0,1 & 0,1 & \\
\hline & $\begin{array}{l}\text { Técnicos y profesionales de nivel } \\
\text { medio }\end{array}$ & 3,1 & 3,2 & 2,3 & 1,8 & 3,0 \\
\hline & Empleados oficina & 3,2 & 1,9 & 2,8 & 2,9 & 2,9 \\
\hline & Trabajadores servicios y vendedores & 14,4 & 10,8 & 13,8 & 13,9 & 18,5 \\
\hline & $\begin{array}{l}\text { Agricultores y trabajadores agr. } \\
\text { cualificados }\end{array}$ & 11,9 & 15,6 & 11,5 & 9,8 & 10,3 \\
\hline & Oficiales, operarios y artesanos & 25,7 & 25,9 & 25,5 & 23,9 & 24,0 \\
\hline & Operadores de instalaciones & 12,1 & 12,0 & 9,5 & 13,7 & 10,1 \\
\hline & Trabajadores no cualificados & 21,6 & 18,8 & 31,0 & 28,6 & 29,8 \\
\hline \multirow{9}{*}{$\begin{array}{l}\text { Secundaria } \\
\text { obligatoria }\end{array}$} & $\begin{array}{l}\text { Dirección empresas y } \\
\text { administraciones públicas }\end{array}$ & 5,5 & 6,9 & 4,0 & 5,1 & 2,4 \\
\hline & $\begin{array}{l}\text { Profesionales, científicos e } \\
\text { intelectuales }\end{array}$ & 0,8 & 0,2 & 0,1 & 0,1 & \\
\hline & $\begin{array}{l}\text { Técnicos y profesionales de nivel } \\
\text { medio }\end{array}$ & 7,2 & 3,4 & 4,3 & 4,1 & 5,1 \\
\hline & Empleados oficina & 8,5 & 6,3 & 6,6 & 8,2 & 6,1 \\
\hline & Trabajadores servicios y vendedores & 19,1 & 16,7 & 19,5 & 21,8 & 25,6 \\
\hline & $\begin{array}{l}\text { Agricultores y trabajadores agr. } \\
\text { cualificados }\end{array}$ & 4,4 & 5,2 & 4,0 & 3,6 & 3,9 \\
\hline & Oficiales, operarios y artesanos & 23,1 & 26,5 & 24,4 & 20,0 & 22,4 \\
\hline & Operadores de instalaciones & 11,0 & 15,4 & 11,2 & 14,7 & 11,0 \\
\hline & Trabajadores no cualificados & 20,5 & 19,3 & 26,0 & 22,3 & 23,6 \\
\hline
\end{tabular}




\begin{tabular}{|c|c|c|c|c|c|c|}
\hline Nivel estudios & Ocupación & 1995 & 2000 & 2005 & 2010 & 2013 \\
\hline \multirow{9}{*}{$\begin{array}{l}\text { Secundaria } \\
\text { Post- } \\
\text { obligatoria }\end{array}$} & $\begin{array}{l}\text { Dirección empresas y } \\
\text { administraciones públicas }\end{array}$ & 7,8 & 8,1 & 5,6 & 7,6 & 4,0 \\
\hline & $\begin{array}{l}\text { Profesionales, científicos e } \\
\text { intelectuales }\end{array}$ & 3,9 & 3,1 & 0,9 & 0,7 & 0,2 \\
\hline & $\begin{array}{l}\text { Técnicos y profesionales de nivel } \\
\text { medio }\end{array}$ & 18,1 & 15,7 & 12,7 & 12,6 & 14,3 \\
\hline & Empleados oficina & 17,9 & 15,6 & 20,3 & 21,9 & 18,0 \\
\hline & Trabajadores servicios y vendedores & 19,3 & 19,0 & 23,0 & 23,9 & 28,4 \\
\hline & $\begin{array}{l}\text { Agricultores y trabajadores agr. } \\
\text { cualificados }\end{array}$ & 1,3 & 2,2 & 2,1 & 1,7 & 2,6 \\
\hline & Oficiales, operarios y artesanos & 15,5 & 18,7 & 14,1 & 11,0 & 14,0 \\
\hline & Operadores de instalaciones & 5,9 & 8,5 & 7,1 & 9,4 & 6,1 \\
\hline & Trabajadores no cualificados & 10,3 & 9,1 & 14,2 & 11,2 & 12,4 \\
\hline \multirow{9}{*}{ Superiores } & $\begin{array}{l}\text { Dirección empresas y } \\
\text { administraciones públicas }\end{array}$ & 8,6 & 11,8 & 6,2 & 7,2 & 4,9 \\
\hline & $\begin{array}{l}\text { Profesionales, científicos e } \\
\text { intelectuales }\end{array}$ & 59,0 & 54,6 & 33,9 & 40,0 & 38,6 \\
\hline & $\begin{array}{l}\text { Técnicos y profesionales de nivel } \\
\text { medio }\end{array}$ & 16,1 & 12,5 & 18,2 & 15,0 & 14,8 \\
\hline & Empleados oficina & 9,0 & 14,1 & 17,2 & 16,5 & 17,4 \\
\hline & Trabajadores servicios y vendedores & 3,6 & 2,8 & 10,3 & 9,0 & 11,6 \\
\hline & $\begin{array}{l}\text { Agricultores y trabajadores agr. } \\
\text { cualificados }\end{array}$ & 0,6 & 0,7 & 0,6 & 0,6 & 0,5 \\
\hline & Oficiales, operarios y artesanos & 1,2 & 1,7 & 6,8 & 5,2 & 6,2 \\
\hline & Operadores de instalaciones & 0,8 & 0,7 & 2,6 & 3,6 & 2,5 \\
\hline & Trabajadores no cualificados & 1,1 & 1,2 & 4,2 & 2,8 & 3,5 \\
\hline
\end{tabular}

Fuente: Elaboración propia a partir de ECV (2005, 2010 y 2013) y PHOGUE (1995 y 2000). 
En relación con los que tienen estudios superiores, si se tiene en cuenta que entre los profesionales se ha producido una reducción de diecinueve puntos porcentuales (del $59 \%$ al 38,6\%) entre 1995 y 2013, es posible sugerir que este grupo esté experimentando un rápido y profundo desclasamiento, que puede deberse, entre otros motivos, a la dificultad de acceso de las nuevas generaciones a estos trabajos, aunque también puede tener su origen en el acceso de otras personas con distinto capital cultural. Este cambio no parece ser efecto exclusivo de la reciente crisis ya que se viene produciendo con antelación al desencadenamiento de la crisis financiera de 2007. No se puede descartar la idea de que una parte de las recientes protestas anti-austeridad y de indignación, en las que la participación estudiantil y juvenil ha sido muy relevante, se deba a la ruptura de las expectativas de movilidad profesionales ascendente entre sectores de clase media o media acomodada.

\subsection{Indicadores de precariedad}

El análisis de la evolución de los indicadores de precariedad entre 1995 y 2013 permite observar la trayectoria seguida y prestar atención a las tendencias antes de la crisis de 2007 y lo sucedido con posterioridad ${ }^{8}$. El indicador de precariedad laboral muestra un aumento de más de dos décimas en el periodo de referencia. El indicador de ingresos sufre una reducción considerable entre 1995 y 2000, pero a partir de este último año aumenta para mantenerse prácticamente estable. El indicador de precariedad de salud, sin embargo, se mantiene estable prácticamente a lo largo de todo el periodo si bien entre la primera y segunda encuesta tuvo una ligera reducción. El indicador de precariedad de vivienda, por último, apenas se mueve durante los últimos ocho años aunque experimentó una disminución considerable entre 1995 y 2000, y algo menor entre 2000 y 2005.

Por otro lado, debe señalarse la existencia de una gran diferencia en la intensidad de las distintas precariedades, pues mientras la laboral y la de ingresos son de tipo medioalto (por encima de seis en una escala de 0 a 10 ), las de salud y vivienda se sitúan ligeramente por encima de 2 y 1 , respectivamente, lo que indicaría un bajo nivel de precariedad global en ambos indicadores.

Existen diferencias importantes entre hombres y mujeres en relación con la evolución reciente de los distintos tipos de precariedad. Las mujeres muestran mayor precariedad que los hombres en todos los indicadores. Sin embargo, las mujeres han reducido la distancia que les separaba de los hombres respecto de la precariedad laboral y de ingresos. Si nos olvidamos por un momento del índice de precariedad de salud que guarda una relación directa con la edad, la precariedad de vivienda y de ingresos afecta especialmente a los jóvenes entre 16-24 y 25-34 años. Su evolución ha sido, no obstante, muy diferente, ya que mientras la precariedad de ingresos ha aumentado, la de vivienda ha disminuido.

${ }^{8}$ A pesar de disponer de datos relativos a un período suficientemente prolongado, la última información corresponde al año 2012 que no comprende la totalidad de años de la crisis financiera y social. 
Tabla 4: Indicadores de precariedad laboral, ingresos, salud y vivienda de 2005 a 2013

\begin{tabular}{|c|c|c|c|c|c|c|}
\hline & & 1995 & 2000 & 2005 & 2010 & 2013 \\
\hline \multirow{3}{*}{$\begin{array}{l}\text { Indicador de } \\
\text { precariedad } \\
\text { laboral }\end{array}$} & Media & 6,6696 & 6,3813 & 6,700 & 6,706 & 6,930 \\
\hline & $\begin{array}{l}\text { Desviación } \\
\text { std. }\end{array}$ & 3,1789 & 3,2994 & 3,124 & 3,076 & 2,997 \\
\hline & $\mathrm{N}$ & 15.577 & 11.850 & 30.375 & 30.953 & 26.883 \\
\hline \multirow{3}{*}{$\begin{array}{l}\text { Indicador de } \\
\text { precariedad } \\
\text { de ingresos }\end{array}$} & Media & 7,0655 & 6,5019 & 6,758 & 6,589 & 6,557 \\
\hline & $\begin{array}{l}\text { Desviación } \\
\text { std. }\end{array}$ & 1,9243 & 2,1031 & 1,894 & 2,0510 & 2,0531 \\
\hline & $\mathrm{N}$ & 16.262 & 12.317 & 30.311 & 30.953 & 26.883 \\
\hline \multirow{3}{*}{$\begin{array}{l}\text { Indicador de } \\
\text { precariedad } \\
\text { de salud }\end{array}$} & Media & 2,2706 & 2,1410 & 2,140 & 2,0809 & 2,163 \\
\hline & $\begin{array}{l}\text { Desviación } \\
\text { std. }\end{array}$ & 2,5679 & 2,4339 & 2,890 & 2,763 & 2,811 \\
\hline & $\mathrm{N}$ & 15.813 & 12.282 & 30.375 & 30.953 & 26.883 \\
\hline \multirow{3}{*}{$\begin{array}{l}\text { Indicador de } \\
\text { precariedad } \\
\text { de vivienda }\end{array}$} & Media & 2,3764 & 1,8454 & 1,575 & 1,342 & 1,311 \\
\hline & $\begin{array}{l}\text { Desviación } \\
\text { std. }\end{array}$ & 1,7364 & 1,4867 & 1,397 & 1,243 & 1,290 \\
\hline & $\mathrm{N}$ & 16.204 & 12.238 & 30.375 & 30.953 & 26.883 \\
\hline
\end{tabular}

Fuente: Elaboración propia a partir de ECV (2005, 2010 y 2013) y PHOGUE (1995 y 2000).

Las personas sin estudios o con estudios primarios muestran los mayores índices de precariedad laboral; nivel de precariedad que va descendiendo paulatinamente a medida que aumenta el capital educativo. En este indicador de precariedad laboral se producen las mayores diferencias entre los que tienen estudios superiores y el resto de niveles de estudio alcanzado. También son los que menos han aumentado su precariedad en los últimos años, seguidos de quienes tienen estudios secundarios postobligatorios.

En el Gráfico 1 puede observarse el diferente comportamiento de las personas con distintos niveles de estudio en los cuatro índices de precariedad. Con cierta facilidad puede apreciarse visualmente que cuanto menor en el capital educativo alcanzado mayor es el grado de precariedad en todos los índices. La precariedad laboral ha afectado más y ha evolucionado peor (aumentando) en los niveles intermedios. La salud ha empeorado entre los que tienen estudios más bajos. El indicador de precariedad de vivienda es el que muestra una mayor estabilidad y menor precariedad, seguramente como resultado del alto porcentaje de viviendas en propiedad existente en España. 
Gráfico 1: Indicadores de precariedad por nivel de estudios de 1995 a 2013
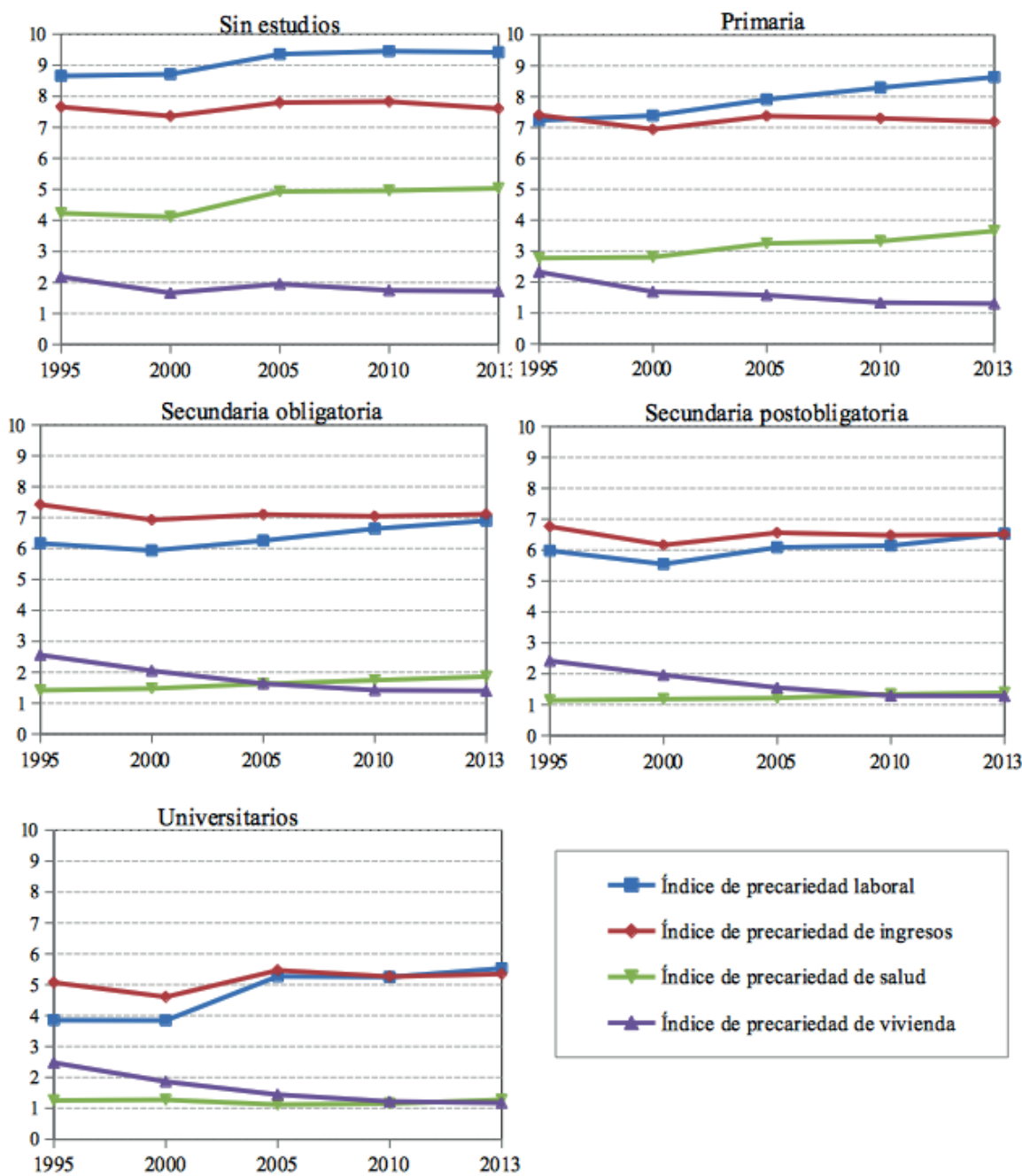

Fuente: Elaboración propia a partir de ECV (2005, 2010 y 2013) y PHOGUE (1995 y 2000).

\section{Análisis multivariable: educación e indicadores de precariedad}

Como ya se adelantó en el apartado metodológico, el estudio sobre la evolución de la influencia del nivel educativo en los procesos de precarización durante el periodo que va desde los años posteriores a la crisis de inicio de la década de 1990 hasta la crisis actual se completa con una serie de análisis multivariables. Se pretende de este modo 
descartar la posibilidad de que la influencia de diversas variables sociodemográficas sobre los indicadores de precariedad presentados en las páginas anteriores sea espuria y esté encubriendo el efecto de otras variables. Teniendo en cuenta el carácter métrico de las variables dependientes (los indicadores de precariedad) se consideró conveniente recurrir al análisis de regresión de mínimos cuadrados ordinarios. Se han realizado cinco análisis de regresión $(1995,2000,2005,2010$ y 2013) para cada uno de los cuatro indicadores de precariedad (laboral, ingresos, salud y vivienda). Por lo que se refiere a las variables independientes se ha incluido siempre la edad, el sexo y el estado civil. En algunos modelos se ha incluido el nivel de estudios, la relación con la actividad o la ocupación, aunque sólo en aquellos casos donde no existía riesgo de multicolinealidad.

Los cinco análisis de regresión efectuados para identificar la influencia de diversas variables sociodemográficas sobre la precariedad laboral (véase Tabla 5) han resultado estadísticamente significativos. De hecho, la $\mathrm{R}^{2}$ corregida oscila entre el 32,7\% de 1995 y el $28,3 \%$ de 2013 , lo que pone de manifiesto el potencial explicativo de los modelos analizados. Cuando se examinan los coeficientes estandarizados beta se descubren algunos resultados relevantes.

En los cinco años de la serie las variables con mayor peso en el modelo son la edad, el sexo, la condición de universitario y la soltería. Ser varón y tener estudios superiores aparecen como las dos variables que predicen una menor precariedad laboral, mientras que con la edad y la soltería sucede lo contrario: su posesión aumenta la probabilidad de verse afectado por la precariedad laboral. En 2013, sigue siendo válido lo que se acaba de afirmar, pero deben señalarse algunos matices respecto a la evolución a lo largo de casi dos décadas. En primer lugar, la condición de varón reduce de manera progresiva su peso como predictor de una menor precariedad laboral, pasando del beta más alto en $1995(-0,299)$ al más bajo en $2013(-0,138)$, lo que significa que las diferencias entre hombres y mujeres en términos de precariedad laboral se han ido reduciendo con el tiempo. En segundo lugar, la posesión de estudios universitarios aumenta su poder predictor de una menor precariedad laboral en 1995 y 2000, pero lo reduce en 2005 para volver a aumentar en 2010 y 2013. Puede decirse, por tanto, que con anterioridad a la crisis económica (en periodo de crecimiento económico), la posesión de estudios universitarios perdió parte de su potencial de protección frente a la precariedad laboral para volver a aumentar en el transcurso de la misma. En tercer lugar, la edad y la soltería aumentan -aunque muy ligeramente- su potencial como predictores de una mayor precariedad laboral en la última década.

Si nos centramos en los $\beta$, las variables con mayor influencia en el indicador de precariedad de ingresos en el modelo realizado para 2013 (véase Tabla 6) son la edad, el nivel de estudios -carecer de ellos o tener estudios de primaria- y la ocupación dedicarse a actividades profesionales, científicas o intelectual o estar parado-. En el modelo de 1995, los factores que más peso tienen como predictor de la precariedad de ingresos son la edad (a menor edad mayor precariedad de ingresos) y carecer de estudios. Por otro lado, lo que más aumenta la probabilidad de no verse afectado por la precariedad de ingresos es la posesión de estudios superiores y dedicarse a una actividad profesional, científica o intelectual. El modelo que se obtiene con los datos de 2000 es muy similar, si bien el hecho de no tener estudios aumenta la probabilidad 
de verse afectado por una mayor precariedad de ingresos, y la posesión de estudios superiores aumenta la protección ante este tipo de precariedad. En el modelo de 2005, el factor que más peso tiene como predictor de la precariedad de ingresos es dedicarse a una actividad profesional, científica o intelectual, pero en sentido negativo, lo que equivale a decir que esta condición reduce la probabilidad de sufrir la precariedad de ingresos. A continuación aparecen otras cuatro condiciones con betas superiores a una décima: estar parado o inactivo y carecer de estudios o tenerlos sólo a nivel de primaria predice una mayor precariedad de ingresos, mientras que contar con estudios superiores es la segunda condición (tras la actividad profesional, científica o intelectual) que más aleja la precariedad de ingresos. Los modelos obtenidos para 2010 y 2013 no modifican lo dicho para 2005, pero conviene señalar que introducen importantes matices en relación con la intensidad de cada condición. En primer lugar, la dedicación a actividades profesionales, científicas o intelectual aumenta año tras año su protección ante la precariedad de ingresos, justo lo contrario de lo que sucede con la posesión de estudios universitarios que, durante los últimos ocho años cubiertos por la serie, reduce esta capacidad de manera constante. En segundo lugar, encontramos que otros factores que aumentan la probabilidad de alejar la precariedad de ingresos son la edad (a mayor edad menor precariedad de ingresos), y trabajar como empleado de oficina o como técnico o profesional de nivel medio. En tercer lugar, sin embargo, las personas paradas, sin estudios o con estudios de primeria aumentan ligeramente la probabilidad de verse afectadas por la precariedad de ingresos.

Por lo que se refiere al indicador de precariedad de salud (Tabla 7), las $\mathrm{R}^{2}$ corregidas oscilan entre el 28,8\% del año 1995 y el $29 \%$ de 2013 . Los resultados de los tres modelos de regresión en este caso son relativamente simples de interpretar. La edad es siempre la variable que mayor influencia tiene en la precariedad de salud, lo que indica que el aumento de este tipo de precariedad se debe más a causas naturales (el envejecimiento) que a factores o variables de carácter social o económico. Hay, pues, una mayor influencia de lo que en palabras de G. Le Blanch podría considerarse como precariedad ontológica frente a la precariedad sociológica. Más allá de esta primera interpretación, los resultados también ponen de manifiesto que carecer de estudios, contar con estudios primarios o encontrarse en situación de inactivo pierden influencia como variables explicativas de la precariedad de salud durante los últimos ocho años de la serie.

Finalmente, por lo que se refiere a los análisis de regresión del indicador de precariedad de vivienda (Tabla 8), hay que mencionar tres aspectos. En primer lugar, salvo el análisis de 2010 , donde alcanza el $15 \%$, las $\mathrm{R}^{2}$ corregidas se sitúan siempre por debajo del seis por ciento, lo que constituye un indicio de que el ajuste de los modelos es modesto. En segundo lugar, la edad es la variable con más poder explicativo sobre la precariedad de vivienda. Este poder explicativo, además, aumenta de manera muy clara en el periodo de referencia. Una posible explicación de este hecho podría estar en dos características de la relación de la población española con la vivienda. De un lado, la mayoritaria cultura de la vivienda en propiedad cuando se compara con otros países de nuestro entorno. De otro lado, el prolongado apoyo de las familias a los jóvenes ha dado lugar a un modelo de emancipación residencial caracterizado por retrasar la 
salida del hogar parental hasta poder acceder a una vivienda en propiedad a través de una hipoteca (Carbajo, 2014). En tercer lugar, carecer de estudios es la condición que en mayor medida explica el verse afectado por una situación de precariedad en relación con la vivienda; de hecho es la variable que más influye en este tipo de precariedad.

Tabla 5: Análisis de regresión (OLS) del indicador de precariedad laboral de 1995 a 2013

\begin{tabular}{|c|c|c|c|c|c|c|c|c|c|c|}
\hline & \multicolumn{2}{|c|}{1995} & \multicolumn{2}{|c|}{2000} & \multicolumn{2}{|c|}{2005} & \multicolumn{2}{|c|}{2010} & \multicolumn{2}{|c|}{2013} \\
\hline $\begin{array}{l}\mathrm{N} \text { (casos } \\
\text { válidos) }\end{array}$ & 16.261 & & 12.317 & & 30.375 & & 30.953 & & 26.883 & \\
\hline $\mathrm{R}$ & 0,573 & & 0,575 & & 0,563 & & 0,551 & & 0,532 & \\
\hline $\mathrm{R}^{2}$ & 0,328 & & 0,331 & & 0,317 & & 0,304 & & 0,283 & \\
\hline $\mathrm{R}^{2}$ corregida & 0,327 & & 0,330 & & 0,317 & & 0,303 & & 0,283 & \\
\hline Error standard & 2,607 & & 2,699 & & 2,582 & & 2,567 & & 2,538 & \\
\hline F (ANOVA) & 632,4 & & 488,3 & & $1.174,826$ & & $1.124,457$ & & 884,832 & \\
\hline Sig. & 0,000 & & 0,000 & & 0,000 & & 0,000 & & 0,000 & \\
\hline $\begin{array}{l}\text { Variables } \\
\text { independientes }\end{array}$ & ß & Sig. & ß & Sig. & $\beta$ & Sig. & $\beta$ & Sig. & $\beta$ & Sig. \\
\hline (Constante) & -- & $* * *$ & -- & $* * *$ & -- & $* * *$ & -- & $* * *$ & -- & $* * *$ \\
\hline Varones & $-0,299$ & $* * *$ & $-0,273$ & $* * *$ & $-0,232$ & $* * *$ & $-0,150$ & $* * *$ & $-0,138$ & $* * *$ \\
\hline Edad $^{2}$ & 0,335 & $* * *$ & 0,320 & $* * *$ & 0,447 & $* * *$ & 0,459 & $* * *$ & 0,430 & $* * *$ \\
\hline Solteros & 0,214 & $* * *$ & 0,203 & $* * *$ & 0,175 & $* * *$ & 0,249 & $* * *$ & 0,240 & $* * *$ \\
\hline Casados & 0,015 & ns & 0,010 & ns & $-0,004$ & ns & 0,029 & $* *$ & 0,012 & ns \\
\hline Separados & $-0,015$ & ns & $-0,021$ & $*$ & $-0,029$ & $* * *$ & $-0,005$ & ns & $-0,003$ & ns \\
\hline Divorciados & $-0,028$ & $* * *$ & $-0,021$ & $* *$ & $-0,025$ & $* * *$ & $-0,019$ & $* *$ & $-0,017$ & $* *$ \\
\hline Sin estudios & 0,074 & $* * *$ & 0,067 & $* * *$ & 0,051 & $* * *$ & 0,048 & $* * *$ & 0,023 & $* * *$ \\
\hline $\begin{array}{l}\text { Secundaria } \\
\text { obligatoria }\end{array}$ & $-0,050$ & $* * *$ & $-0,083$ & $* * *$ & $-0,048$ & $* * *$ & $-0,053$ & $* * *$ & $-0,076$ & $* * *$ \\
\hline $\begin{array}{l}\text { Secundaria } \\
\text { postobligatoria }\end{array}$ & $-0,088$ & $* * *$ & $-0,143$ & $* * *$ & $-0,067$ & $* * *$ & $-0,112$ & $* * *$ & $-0,118$ & $* * *$ \\
\hline Superiores & $-0,278$ & $* * *$ & $-0,328$ & $* * *$ & $-0,189$ & $* * *$ & $-0,246$ & $* * *$ & $-0,276$ & $* * *$ \\
\hline Unión Europea & $-0,001$ & ns & 0,008 & ns & $-0,012$ & $*$ & 0,039 & $* * *$ & 0,013 & $*$ \\
\hline $\begin{array}{l}\text { Resto del } \\
\text { mundo }\end{array}$ & 0,002 & ns & 0,010 & ns & $-0,016$ & $* *$ & 0,029 & $* * *$ & 0,039 & $* * *$ \\
\hline
\end{tabular}

Fuente: Elaboración propia a partir de PHOGUE (1995 y 2000) y ECV (2005, 2010 y 2013) $* * *(\mathrm{p}<0.001) ; * *(\mathrm{p}<0.01) ; *(\mathrm{p}<0.05) ;$ ns (no significativo) 
Tabla 6: Análisis de regresión (OLS) del indicador de precariedad de ingresos de 1995 a 2013

\begin{tabular}{|c|c|c|c|c|c|c|c|c|c|c|}
\hline & \multicolumn{2}{|c|}{1995} & \multicolumn{2}{|c|}{2000} & \multicolumn{2}{|c|}{2005} & \multicolumn{2}{|c|}{2010} & \multicolumn{2}{|c|}{2013} \\
\hline $\mathrm{N}$ (casos válidos) & 16.261 & & 12.316 & & 30.375 & & 30.953 & & 26.883 & \\
\hline $\mathrm{R}$ & 0,496 & & 0,500 & & 0,477 & & 0,501 & & 0,505 & \\
\hline $\mathrm{R}^{2}$ & 0,246 & & 0,250 & & 0,227 & & 0,251 & & 0,255 & \\
\hline $\mathrm{R}^{2}$ corregida & 0,245 & & 0,249 & & 0,227 & & 0,250 & & 0,254 & \\
\hline Error standard & 1,67251 & & 1,82253 & & 1,665 & & 1,77615 & & 1,773 & \\
\hline F (ANOVA) & 251,685 & & 195,483 & & 424,689 & & 492,383 & & 436,793 & \\
\hline Sig. & 0,000 & & 0,000 & & 0,000 & & 0,000 & & 0,000 & \\
\hline $\begin{array}{l}\text { Variables } \\
\text { independientes }\end{array}$ & $\beta$ & Sig. & ß & Sig. & B & Sig. & $\beta$ & Sig. & $\beta$ & Sig. \\
\hline (Constante) & & $* * *$ & & $* * *$ & -- & $* * *$ & -- & $* * *$ & -- & $* * *$ \\
\hline Varones & 0,033 & $* * *$ & 0,001 & ns & $-0,007$ & ns & $-0,016$ & $* *$ & $-0,019$ & $* *$ \\
\hline Edad $^{2}$ & $-0,322$ & $* * *$ & $-0,270$ & $* * *$ & $-0,023$ & $* *$ & $-0,096$ & $* * *$ & $-0,148$ & $* * *$ \\
\hline Solteros & $-0,048$ & $* *$ & $-0,016$ & ns & 0,043 & $* * *$ & 0,015 & ns & $-0,016$ & ns \\
\hline Casados & 0,030 & $*$ & 0,070 & $* * *$ & 0,017 & ns & 0,023 & $*$ & 0,012 & ns \\
\hline Separados & 0,000 & ns & 0,008 & ns & 0,032 & $* * *$ & 0,038 & $* * *$ & 0,035 & $* * *$ \\
\hline Divorciados & $-0,020$ & $* *$ & 0,003 & ns & 0,021 & $* * *$ & 0,037 & $* * *$ & 0,053 & $* * *$ \\
\hline Sin estudios & 0,309 & $* * *$ & 0,306 & $* * *$ & 0,104 & $* * *$ & 0,131 & $* * *$ & 0,124 & $* * *$ \\
\hline Primaria & 0,236 & $* * *$ & 0,228 & $* * *$ & 0,132 & $* * *$ & 0,143 & $* * *$ & 0,142 & $* * *$ \\
\hline $\begin{array}{l}\text { Secundaria } \\
\text { obligatoria }\end{array}$ & 0,116 & $* * *$ & 0,119 & $* * *$ & 0,076 & $* * *$ & 0,076 & $* * *$ & 0,082 & $* * *$ \\
\hline Superiores & $-0,144$ & $* * *$ & $-0,160$ & $* * *$ & $-0,115$ & $* * *$ & $-0,088$ & $* * *$ & $-0,085$ & $* * *$ \\
\hline $\begin{array}{l}\text { Dirección de } \\
\text { empresas y } \\
\text { administraciones }\end{array}$ & $-0,055$ & $* * *$ & $-0,124$ & $* * *$ & $-0,052$ & $* * *$ & $-0,025$ & $* * *$ & $-0,083$ & $* * *$ \\
\hline $\begin{array}{l}\text { Profesionales, } \\
\text { científicos e } \\
\text { intelectuales }\end{array}$ & $-0,139$ & $* * *$ & $-0,125$ & $* * *$ & $-0,198$ & $* * *$ & $-0,247$ & $* * *$ & $-0,244$ & $* * *$ \\
\hline $\begin{array}{l}\text { Técnicos y } \\
\text { profesionales de } \\
\text { nivel medio }\end{array}$ & $-0,102$ & $* * *$ & $-0,087$ & $* * *$ & $-0,095$ & $* * *$ & $-0,109$ & $* * *$ & $-0,106$ & $* * *$ \\
\hline
\end{tabular}




\begin{tabular}{|l|l|l|l|l|l|l|l|l|l|l|}
\hline $\begin{array}{l}\text { Empleados } \\
\text { oficina }\end{array}$ & $-0,061$ & $* * *$ & $-0,067$ & $* * *$ & $-0,096$ & $* * *$ & $-0,121$ & $* * *$ & $-0,130$ & $* * *$ \\
\hline $\begin{array}{l}\text { Trabajadores } \\
\text { servicios y } \\
\text { vendedores }\end{array}$ & $-0,015$ & $\mathrm{~ns}$ & $-0,013$ & $\mathrm{~ns}$ & $-0,005$ & $\mathrm{~ns}$ & $-0,012$ & $*$ & $-0,021$ & $* *$ \\
\hline $\begin{array}{l}\text { Agricultores } \\
\text { y trabajadores } \\
\text { agropecuarios }\end{array}$ & 0,021 & $* *$ & 0,021 & $*$ & 0,046 & $* * *$ & 0,051 & $* * *$ & 0,020 & $* * *$ \\
\hline $\begin{array}{l}\text { Operadores de } \\
\text { instalaciones }\end{array}$ & $-0,008$ & $\mathrm{~ns}$ & $-0,029$ & $* *$ & $-0,027$ & $* * *$ & $-0,043$ & $* * *$ & $-0,034$ & $* * *$ \\
\hline $\begin{array}{l}\text { Trabajadores no } \\
\text { cualificados }\end{array}$ & 0,024 & $* *$ & 0,030 & $* *$ & 0,035 & $* * *$ & 0,040 & $* * *$ & 0,040 & $* * *$ \\
\hline Ayuda familiar & 0,025 & $* * *$ & $-0,008$ & $\mathrm{~ns}$ & 0,036 & $* * *$ & 0,027 & $* * *$ & 0,018 & $* *$ \\
\hline Inactivo & 0,088 & $* * *$ & 0,042 & $* *$ & 0,118 & $* * *$ & 0,088 & $* * *$ & 0,056 & $* * *$ \\
\hline Parados & 0,096 & $* * *$ & 0,089 & $* * *$ & 0,124 & $* * *$ & 0,156 & $* * *$ & 0,182 & $* * *$ \\
\hline
\end{tabular}

Fuente: Elaboración propia a partir de PHOGUE (1995 y 2000) y ECV (2005, 2010 y 2013). $* * *(p<0.001) ; * *(p<0.01) ; *(p<0.05) ;$ ns (no significativo).

Tabla 7: Análisis de regresión (OLS) del indicador de precariedad salud de 1995 a 2013

\begin{tabular}{|c|c|c|c|c|c|c|c|c|c|c|}
\hline \multirow[b]{2}{*}{ N (casos válidos) } & \multicolumn{2}{|c|}{1995} & \multicolumn{2}{|c|}{2000} & \multicolumn{2}{|c|}{2005} & \multicolumn{2}{|c|}{2010} & \multicolumn{2}{|c|}{2013} \\
\hline & 15.812 & & 12.281 & & 30.375 & & 30.953 & & 26.883 & \\
\hline $\mathrm{R}$ & 0,537 & & 0,510 & & 0,531 & & 0,540 & & 0,539 & \\
\hline $\mathrm{R}^{2}$ & 0,289 & & 0,261 & & 0,282 & & 0,291 & & 0,290 & \\
\hline $\mathrm{R}^{2}$ corregida & 0,288 & & 0,260 & & 0,281 & & 0,291 & & 0,290 & \\
\hline Error standard & 2,16669 & & 2,09408 & & 2,450 & & 2,327 & & 2,369 & \\
\hline $\mathrm{F}$ (ANOVA) & 493,190 & & 332,525 & & 915,235 & & 978,381 & & 844,510 & \\
\hline Sig. & 0,000 & & 0,000 & & 0,000 & & 0,000 & & 0,000 & \\
\hline $\begin{array}{l}\text { Variables } \\
\text { independientes }\end{array}$ & $\beta$ & Sig. & $\beta$ & Sig. & $\beta$ & Sig. & $\beta$ & Sig. & $\beta$ & Sig. \\
\hline (Constante) & & ns & & ns & -- & ns & -- & $* * *$ & -- & $* * *$ \\
\hline Varones & 0,004 & ns & 0,002 & $\mathrm{~ns}$ & $-0,014$ & $* *$ & $-0,024$ & $* * *$ & $-0,025$ & $* * *$ \\
\hline Edad $^{2}$ & 0,341 & $* * *$ & 0,307 & $* * *$ & 0,354 & $* * *$ & 0,341 & $* * *$ & 0,340 & $* * *$ \\
\hline Solteros & 0,043 & $* *$ & 0,038 & $*$ & $-0,021$ & $\mathrm{~ns}$ & $-0,073$ & $* * *$ & $-0,092$ & $* * *$ \\
\hline Casados & 0,022 & ns & $-0,004$ & ns & $-0,036$ & $* * *$ & $-0,085$ & $* * *$ & $-0,095$ & $* * *$ \\
\hline Separados & 0,029 & $* * *$ & 0,022 & $*$ & 0,012 & $*$ & 0,006 & ns & $-0,011$ & ns \\
\hline Divorciados & 0,011 & ns & 0,036 & $* * *$ & $-0,004$ & ns & 0,003 & ns & 0,005 & ns \\
\hline
\end{tabular}




\begin{tabular}{|l|l|l|l|l|l|l|l|l|l|l|}
\hline Sin estudios & 0,213 & $* * *$ & 0,220 & $* * *$ & 0,131 & $* * *$ & 0,124 & $* * *$ & 0,123 & $* * *$ \\
\hline Primaria & 0,134 & $* * *$ & 0,141 & $* * *$ & 0,123 & $* * *$ & 0,078 & $* * *$ & 0,114 & $* * *$ \\
\hline $\begin{array}{l}\text { Secundaria } \\
\text { obligatoria }\end{array}$ & 0,035 & $* * *$ & 0,050 & $* * *$ & 0,043 & $* * *$ & 0,027 & $* * *$ & 0,043 & $* * *$ \\
\hline Superiores & $-0,005$ & $\mathrm{~ns}$ & 0,003 & $\mathrm{~ns}$ & $-0,014$ & $*$ & $-0,037$ & $* * *$ & $-0,023$ & $* * *$ \\
\hline $\begin{array}{l}\text { Empresario/ } \\
\text { autónomo }\end{array}$ & 0,015 & $\mathrm{~ns}$ & 0,027 & $\mathrm{~ns}$ & $-0,007$ & $\mathrm{~ns}$ & $-0,034$ & $* * *$ & $-0,024$ & $* * *$ \\
\hline Asalariado & $-0,009$ & $\mathrm{~ns}$ & 0,067 & $\mathrm{~ns}$ & 0,038 & $* * *$ & $-0,077$ & $* * *$ & $-0,059$ & $* * *$ \\
\hline Inactivo & 0,113 & $* *$ & 0,175 & $* *$ & 0,141 & $* * *$ & 0,065 & $* * *$ & 0,055 & $* * *$ \\
\hline
\end{tabular}

Fuente: Elaboración propia a partir de PHOGUE (1995 y 2000) y ECV (2005, 2010 y 2013). $* * *(p<0.001) ; * *(p<0.01) ; *(p<0.05) ;$ ns (no significativo).

Tabla 8: Análisis de regresión (OLS) del indicador de precariedad de vivienda de 1995 a 2013

\begin{tabular}{|c|c|c|c|c|c|c|c|c|c|c|}
\hline \multirow[b]{2}{*}{$\mathrm{N}$ (casos válidos) } & \multicolumn{2}{|c|}{1995} & \multicolumn{2}{|c|}{2000} & \multicolumn{2}{|c|}{2005} & \multicolumn{2}{|c|}{2010} & \multicolumn{2}{|c|}{2013} \\
\hline & 16.203 & & 12.237 & & 30.375 & & 30.953 & & 26.883 & \\
\hline $\mathrm{R}$ & 0,188 & & 0,219 & & 0,169 & & 0,223 & & 0,236 & \\
\hline $\mathrm{R}^{2}$ & 0,035 & & 0,048 & & 0,028 & & 0,050 & & 0,056 & \\
\hline $\mathrm{R}^{2}$ corregida & 0,034 & & 0,047 & & 0,028 & & 0,049 & & 0,055 & \\
\hline Error standard & 1,70626 & & 1,45147 & & 1,377 & & 1,212 & & 1,254 & \\
\hline F (ANOVA) & 37,095 & & 38,591 & & 55,570 & & 101,611 & & 99,465 & \\
\hline Sig. & 0,000 & & 0,000 & & 0,000 & & 0,000 & & 0,000 & \\
\hline $\begin{array}{l}\text { Variables } \\
\text { independientes }\end{array}$ & $\beta$ & Sig. & B & Sig. & ß & Sig. & $\beta$ & Sig. & $\beta$ & Sig. \\
\hline (Constante) & & $* * *$ & & $* * *$ & -- & $\mathrm{ns}$ & -- & $* * *$ & -- & $* * *$ \\
\hline Varones & $-0,024$ & $*$ & $-0,030$ & $* *$ & $-0,019$ & $* *$ & $-0,007$ & ns & $-0,002$ & ns \\
\hline Edad $^{2}$ & $-0,188$ & $* * *$ & $-0,252$ & $* * *$ & $-0,082$ & $* * *$ & $-0,150$ & $* * *$ & $-0,169$ & $* * *$ \\
\hline Solteros & $-0,147$ & $* * *$ & $-0,218$ & $* * *$ & $-0,004$ & ns & $-0,033$ & $* *$ & $-0,020$ & ns \\
\hline Casados & $-0,067$ & $* * *$ & $-0,096$ & $* * *$ & $-0,065$ & $* * *$ & $-0,089$ & $* * *$ & $-0,084$ & $* * *$ \\
\hline Separados & 0,048 & $* * *$ & $-0,001$ & ns & 0,030 & $* * *$ & 0,030 & $* * *$ & 0,024 & $* * *$ \\
\hline Divorciados & 0,033 & $* * *$ & 0,027 & $* *$ & 0,021 & $* *$ & 0,025 & $* * *$ & 0,029 & $* * *$ \\
\hline Sin estudios & 0,009 & $\mathrm{~ns}$ & $-0,001$ & $\mathrm{~ns}$ & 0,089 & $* * *$ & 0,134 & $* * *$ & 0,127 & $* * *$ \\
\hline Primaria & 0,004 & ns & $-0,037$ & $* *$ & 0,037 & $* * *$ & 0,087 & $* * *$ & 0,082 & $* * *$ \\
\hline $\begin{array}{l}\text { Secundaria } \\
\text { obligatoria }\end{array}$ & 0,015 & ns & 0,007 & ns & 0,016 & $*$ & 0,046 & $* * *$ & 0,034 & $* * *$ \\
\hline Superiores & 0,007 & ns & $-0,023$ & $* *$ & $-0,044$ & $* * *$ & $-0,019$ & $* *$ & $-0,038$ & $* * *$ \\
\hline
\end{tabular}




\begin{tabular}{|l|l|l|l|l|l|l|l|l|l|l|}
\hline $\begin{array}{l}\text { Empresario/ } \\
\text { autónomo }\end{array}$ & $-0,044$ & $* * *$ & $-0,074$ & $* * *$ & $-0,035$ & $* * *$ & $-0,024$ & $* * *$ & $-0,010$ & $\mathrm{~ns}$ \\
\hline Asalariado & 0,007 & $\mathrm{~ns}$ & $-0,031$ & $\mathrm{~ns}$ & 0,007 & $\mathrm{~ns}$ & $-0,014$ & $\mathrm{~ns}$ & 0,027 & $*$ \\
\hline Parado & 0,038 & $* * *$ & $-0,004$ & $\mathrm{~ns}$ & 0,061 & $* * *$ & 0,093 & $* * *$ & 0,089 & $* * *$ \\
\hline Estudiante & $-0,046$ & $* * *$ & $-0,101$ & $* * *$ & $-0,075$ & $* * *$ & $-0,079$ & $* * *$ & $-0,066$ & $* * *$ \\
\hline Jubilado, retirado & 0,022 & $\mathrm{~ns}$ & $-0,018$ & $\mathrm{~ns}$ & 0,004 & $\mathrm{~ns}$ & $-0,010$ & $\mathrm{~ns}$ & 0,003 & $\mathrm{~ns}$ \\
\hline Tareas del hogar & $-0,027$ & $*$ & $-0,070$ & $* * *$ & $-0,016$ & $\mathrm{~ns}$ & $-0,021$ & $*$ & 0,023 & $* *$ \\
\hline
\end{tabular}

Fuente: elaboración propia a partir de PHOGUE (1995 y 2000) y ECV (2005, 2010 y 2013)

$* * *(\mathrm{p}<0.001) ; * *(\mathrm{p}<0.01) ; *(\mathrm{p}<0.05) ; \mathrm{ns}$ (no significativo)

\section{Discusión}

El capital educativo se ha enfrentado en las últimas décadas a dos procesos concomitantes: su progresiva expansión y su paulatina devaluación. La tradicional ecuación que asocia educación y afluencia -y la contraria: menos educación con más precariedad- parece estar sufriendo profundas transformaciones. La sospecha sobre el declive de la relación, dada por supuesto y tomada como evidencia social, entre capital cultural y condiciones de vida ha sido la hipótesis que ha guiado este artículo: ¿es cierto que disponer de más educación posibilita mejores condiciones de existencia?, ¿en qué aspectos de la vida cotidiana de las personas?, ¿su ritmo se acelera o se frena?

Para responder a estas tres primeras preguntas se ha construido una herramienta metodológica a partir de las encuestas PHOGUE y ECV del INE. Esta tarea ha consistido en elaborar cuatro indicadores de afluencia-precariedad mediante la agregación de distintas variables para, posteriormente, utilizarlos para situar a la población española. El resultado ha sido que a menor nivel de estudios se observa mayor nivel de precariedad y a mayor nivel de estudios mayor grado de afluencia en todos los tipos de precariedad: laboral, de ingresos, de salud y de vivienda. En cuanto a los distintos tipos de precariedad-afluencia parecen existir dos dinámicas muy diferentes: mientras las medias en la dimensión laboral y de ingresos supera el punto medio (5) las medias de salud (con excepción de los que no tienen estudios que se sitúan en las edades más elevadas) y de vivienda se sitúan por debajo del 3. Desde nuestro punto de vista, los resultados de la aplicación de la herramienta metodológica que son estos indicadores pueden contribuir a arrojar luz a un debate que cada vez tiene más de ideológico y menos de científico.

Una cuestión fundamental que se plantea este artículo tiene que ver con el impacto de la crisis o, dicho de otro modo, ya que podemos observar el comportamiento de ciertas dimensiones de la existencia de las personas tanto en un período de un significativo crecimiento económico como en un momento de profunda crisis social, ¿tiene el mismo efecto el capital cultural en ambos momentos?, ¿qué nos muestra su evolución en un período de tiempo prolongado?

Con anterioridad a la gran depresión que comienza a manifestarse a finales de 2007 e inicio de 2008, la precariedad laboral había aumentado ligeramente en el período 
1995-2005, la situación de los ingresos medios había mejorado un poco, al igual que la salud y la vivienda con índices menores de precariedad. La llegada de la crisis cambia de manera significativa esta situación: la precariedad laboral aumenta; la de ingresos se sitúa por encima de la existente en el año 2000; la de salud se mantiene bastante estable aunque ligeramente por encima de la que había en el año 2000; la afluencia en relación con el entorno vital (equipamiento de la vivienda y condiciones del barrio) ha crecido ininterrumpidamente entre 1995 y 2013, si bien se observa una progresiva reducción de su ritmo.

En el período comprendido entre 2005 y 2013, la precariedad laboral empeora en todos los niveles de estudio, pero la diferencia es mayor a menor capital cultural. Algo similar se puede afirmar de la precariedad de ingresos, ya que mientras la mayoría de niveles de estudio se mantiene estable con una ligera tendencia a la reducción, los que tienen estudios superiores mejoran ligeramente sus ingresos. Los índices de salud han empeorado en todos los niveles de estudio, y los índices de calidad de la vivienda y del entorno han mejorado en todos los niveles. Todo indica que los que disponen de estudios primarios son los que más han visto empeorar su situación vital en tres de las dimensiones analizadas (laboral, de ingresos y de salud). Por el contrario, las personas con estudios superiores son quienes menos han empeorado en los índices laboral y de salud, y los que han mejorado en los índices de ingresos y vivienda.

En relación con la influencia del nivel educativo en los procesos de precarizaciónafluencia y su evolución desde el final de la crisis de la década de 1990 hasta el año 2013, los cinco análisis multivariables realizados han resultado estadísticamente significativos. 1) La $\mathrm{R}^{2}$ corregida del indicador de precariedad laboral varía entre el $32,7 \%$ de 1995 y el $28,3 \%$ de 2013 . Tener estudios superiores es una de las variables que predice una menor precariedad laboral. Su poder de predicción aumenta entre 1995 y 2000, disminuye en 2005 y vuelve a crecer en 2010 y 2013. 2) La R ${ }^{2}$ corregida del indicador de precariedad de ingresos varía entre el $24,5 \%$ de 1995 y el $25,4 \%$ de 2013. Carecer de estudios o tener estudios primarios es una de las variables con mayor influencia en el indicador de precariedad-afluencia de ingresos. En 1995, la posesión de estudios universitarios es lo que más aumenta la probabilidad de no verse afectado por la precariedad de ingresos. Tanto en el año 2000 como en 2005, carecer de estudios incrementaba la probabilidad de verse afectado por la precariedad de ingresos y tener estudios universitarios proporciona cierta protección frente a esta circunstancia. Durante la crisis, en 2010 y 2013, la posesión de estudios universitarios reduce esta capacidad de manera constante. 3) $\mathrm{La} \mathrm{R}^{2}$ corregida del indicador de precariedad de salud permanece estable entre el $28,8 \%$ de 1995 y el $29 \%$ de 2013 . Tanto carecer de estudios como contar con estudios primarios, pierden influencia como variables explicativas de la precariedad de salud durante los últimos años analizados. 4) En relación con la precariedad de vivienda el ajuste de los modelos es modesto. La edad es la variable con más poder explicativo, y carecer de estudios es la condición que explica en mayor medida la precariedad de vivienda.

Si bien los indicadores utilizados en este estudio se han mostrado socialmente significativos, en la medida que nos ayudan a entender algunos factores que influyen en la dinámica del mercado laboral de la población, no podemos olvidar que ciertos 
procesos de transformación profunda del mundo del trabajo pueden estar influyendo en los resultados globales, ya que en las últimos años se han puesto en marcha importantes reformas legislativas y estructurales. Algo similar, seguramente, está pasando con la estructura de ingresos de la población española, donde la solidaridad intergeneracional adquiere un nivel bastante más elevado que el de otras sociedades de nuestro entorno geográfico. La dimensión más clara de interpretar parece ser la relacionada con la salud, marcada por la dimensión de la precariedad ontológica, aunque deberemos estar atentos a la dimensión sociológica y su impacto en el futuro inmediato. Las condiciones relativas a la calidad de vida residencial requieren de un instrumental de análisis algo más sofisticado que el que hemos podido utilizar, y que atienda de manera más pormenorizada a las dinámicas recientes de mejora emprendidas en décadas anteriores y que pueden haberse frenado como consecuencia del impacto de la crisis. Otro tanto creemos que debería aplicarse a la comprensión de la crisis del ladrillo, con su cadena de lanzamientos y desahucios a los que parecen ser poco sensibles los datos utilizados.

Hay algunas preguntas que han aparecido durante la interpretación de los datos y que no hemos podido responder, pero que pueden ser relevantes para una mejor comprensión e interpretación de la información utilizada. Tal es el caso de variables que guardan una cercana, si no directa, relación con el capital educativo como la ocupación que se desempeña. También se debería considerar una dimensión temporal que tiene que ver, por un lado, con la herencia y, por otro lado, con la reproducción y la transformación social a largo plazo como el cambio generacional. Esperamos poder continuar nuestra reflexión en esta doble línea en próximos trabajos.

\section{Bibliografía}

Alteri, L. y L. Raffini (2007): “Trabajadores precarios, ¿ciudadanos precarios?”, Sistema. Revista de Ciencias Sociales, 197-198, pp. 43-58.

Ariño, A., M. Hernández, R. Llopis, P. Navarro y B. Tejerina (2008): El oficio de estudiar en la Universidad: Compromisos flexibles, Valencia, PUV.

Ariño, A. y R. Llopis (dirs.) (2011): ¿Universidad sin clases? Condiciones de vida de los estudiantes universitarios en España (Eurostudent IV), Madrid, Ministerio de Educación y Cultura.

Arriola, J. y L. Vasapollo (2005): Flexibles y precarios. La opresión del trabajo en el nuevo capitalismo europeo, Madrid, El Viejo Topo.

Aysa-Lastra, M. y L. Cachón (2013): "Movilidad ocupacional segmentada: el caso de los inmigrantes no comunitarios en España", Revista Española de Investigaciones Sociológicas, 144, 23-47.

Banyuls, J., E. Cano, J. Vicente Ficher y A. Sánchez (2003): "Empleo informal y precariedad laboral: las empleadas del hogar", Sociología del Trabajo, 47, pp. 75105.

Barbier, J. C. (2005) : "La précarité, une catégorie française à l'épreuve de la comparaison internationale", Revue Française de Sociologie, 46, pp. 351-371.

Bauman, Z. (2000): Trabajo, consumismo y nuevos pobres, Barcelona, Gedisa. 
Bauman, Z. (2005): Vidas desperdiciadas. La modernidad y sus parias, Barcelona, Paidós.

Bilbao, A. (1998): "El trabajador precario", Arxius de Sociología, 2, pp. 39-56.

Bilbao, A. (1999): "La globalización y las relaciones laborales", Cuadernos de Relaciones Laborales, 15, pp. 123-137.

Bilbao, A., E. Cano y G. Standing (2000): Precariedad laboral. Flexibilidad y desregulación, Valencia, Germania.

Blanch, G. le (2007): Vies ordinaires, vies précaires, París, Seuil.

Blanco, C. (1995): "El inmigrante como sujeto marginado. Claves interpretativas", en J. P. Alvite (coord.), Racismo, antirracismo e inmigración, San Sebastián, Gakoa.

Butler, J. (2006): Vida precaria. Poder del duelo y la violencia, Barcelona, Paidós.

Cachón, L. (1997): "Segregación sectorial de los inmigrantes en el mercado de trabajo en España", Cuadernos de Relaciones Laborales, 10, pp. 49-73.

Cachón, L. (2009): La 'España inmigrante': marco discriminatorio, mercado de trabajo y politicas de integración. Barcelona, Anthropos.

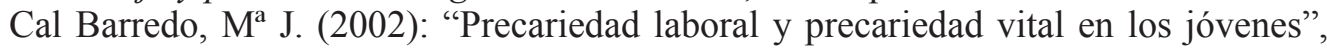
Inguruak, Revista de Sociología, 32, pp. 67-87.

Carbajo, D. (2014): Vivir en la precariedad. Trayectorias y estrategias residenciales de la juventud en la Comunidad Autónoma del País Vasco, Tesis Doctoral, Bilbao, Universidad del País Vasco.

Carbajo, D. (2015): Los procesos de precarización de la juventud en la CAPV a través de sus trayectorias residenciales, Vitoria-Gasteiz, Servicio Central de Publicaciones del Gobierno Vasco.

Carnoy, M. (2001): El trabajo flexible en la era de la información, Madrid, Alianza.

Carrasque Oto, P. yT. Torns Martín (2007): "Cultura de la precariedad: conceptualización, pautas y dimensiones. Una aproximación desde la perspectiva de género", Sociedad y Utopía, 19, pp. 139-156.

Casal, J. (1996): "Modos emergentes de transición a la vida adulta en el umbral del siglo XXI: Aproximación sucesiva, precariedad y desestructuración", Revista Española de Investigaciones Sociológicas, 75, pp. 296-316.

Casal, J., M. García, R. Merino y M. Quesada (2006): “Cambios en las modalidades de transición en los países de capitalismo informal”, Papers, 79, pp. 195-233.

Castillo, J. J. (1995): “Distritos y detritos industriales. La nueva organización productiva en España", Revista Internacional de Sociología, 10, pp. 29-58.

Cavia, B. y M. Martínez (2013): "La construcción de lo precario: la investigación sobre la precariedad en la literatura sociológica española y algunas aportaciones sobre sus derivas", en B. Tejerina, B. Cavia, S. Fortino y J. A. Calderón (eds.), Crisis y precariedad vital. Trabajo, prácticas sociales y modos de vida en Francia y España, Valencia, Tirant Lo Blanch, pp. 45-66.

Cingolani, P. (2005): La précarité, París, PUF.

Colectivo Ioé (1999): Inmigración y trabajo en España. Trabajadores inmigrantes en el sector de la hostelería, Madrid, Ministerio de Trabajo y Asuntos Sociales.

Colectivo Ioé (2001): Mujer, Inmigración y Trabajo, Madrid, Ministerio de Trabajo y Asuntos Sociales. 
Díaz Moreno, V. (2007): "Los jóvenes y las nuevas formas de movilización social y política”, Sistema. Revista de Ciencias Sociales, 197-198, pp. 283-295.

Díaz-Salazar, R. (ed.) (2003): Trabajadores precarios. El proletariado del siglo XXI, Madrid, Hoac.

Fortino, S., B. Tejerina, B. Cavia y J. A. Calderón (2012): Crise sociale et précarité. Travail, modes de vie et résistances en France et en Espagne, Nîmes, Champ Social.

Frade, C. e I. Darmon (2005): "New modes of business organization and precarious employment: towards the recommodification of labour?", Journal of European Social Policy, 15, pp. 107-121.

Gálvez Biesca, S. (2005): "La cultura de la precariedad o los cursos y costumbres de las empresas. Un balance histórico del impacto generacional de la reforma del Estado de los trabajadores de 1984", Sociedad y Utopía, 25, pp. 19-52.

Gálvez Biesca, S. (2007): "La generación de la cultura de la precariedad: una aproximación desde la historia del movimiento obrero", Sociedad y Utopía, 29, pp. 333-366.

García García, S. (2006): "Discurso sobre el hacinamiento: una oportunidad para reflexionar sobre el conflicto", Cuadernos de Trabajo Social, 19, pp. 55-87.

Gónzalez, Ma M., I. Jímenez y B. Morgado (2004): "Los retos de la maternidad en solitario", Revista de Estudios de Juventud, 67, pp. 145-163.

Gruel, L., O. Galland y G. Houzel (2009): Les étudiants en France: Histoire et sociologie d'une nouvelle jeunesse, Rennes, Presses Universitaires de Rennes.

Hernández Aristu, J. (2002): "Jóvenes entre la familia, la formación y el empleo: estructuras de apoyo y transiciones", Revista de Estudios de Juventud, 56, pp. 119128.

INE (2005): Encuesta de Condiciones de Vida. Metodología [revisada en 2013]. Madrid: INE. http://www.ine.es/daco/daco42/condivi/ecv_metodo.pdf

IVIE (2013): Capital Humano, Valencia, IVIE $\bar{N}^{\circ} 144$.

Jurado Guerrero, T. (2007): "La precariedad temporal-salarial y sus efectos sobre la formación familiar", Sociedad y Utopía, 29, pp. 367-404.

Lago, I. (2007): "Precariedad laboral y participación electoral desigual", Sociedad y Utopía, 29, pp. 451-461.

Lamo de Espinosa, R. (2006): "De la contra-reforma a la contra-cultura. Cambio social y cambio cultural en España", en E. Bericat (coord.), El cambio social en España: Visiones y retos de futuro, Sevilla, Centro de Estudios Andaluces.

Laparra, M. (2007): La construcción del empleo precario: dimensiones, causas y tendencias de la precariedad laboral, Madrid, Fundación FOESSA.

La Roca F. y A. Sánchez (eds.) (1996): Economía Crítica. Trabajo y medio ambiente, Valencia, Universidad de Valencia.

Machado Pais, J. (2007): Chollos, chapuzas, changas. Jóvenes, trabajo precario y futuro, Anthropos, Barcelona, UAM-Azcapotzalco.

Martínez Veiga, U. (1997): La integración social de los inmigrantes extranjeros en España, Madrid, Trotta. 
Martínez Veiga, U. (1999): Pobreza, segregación y exclusión espacial, Barcelona, Icaria.

Moreno Fernández, L. (2000): Ciudadanos precarios. La última red de protección social, Barcelona, Ariel.

Moreno Mínguez, A. (2000): "Las familias monoparentales", Revista Internacional de Sociología, 26, pp. 39-63.

Morente Mejías, F. e I. Barroso (2003): "La precariedad familiar ante la pobreza de la infancia. Una aproximación sociológica", Portuaria. Revista de Trabajo Social, 3 , pp. 67-88.

Mur y Petit, R. (2003): Situacions de pobreza i exclusió social a la provincia de Barcelona, Barcelona, Institut d'Estudis Regionals i Metropolitans de Barcelona.

OCDE (2014): Estudios económicos de la OCDE. España. Septiembre. www.oecd. org/economy/surveys/Spain-Overview-Spanish.pdf.

Paugam, S. (2000): Le salarié de la précarité. Les nouvelles formes de l'intégration professionnelle, París, PUF.

Pérez-Agote, A., B. Tejerina y E. Santamaría (2001): La inserción laboral de los jóvenes en Bizkaia, Bilbao, BBK Gazte Lanbidean Fundazioa.

Pérez-Agote, A., B. Tejerina y E. Santamaría (2005): Transformaciones y tendencias de la cultura del trabajo en Bizkaia. Enfoque cuantitativo, Bilbao, Gazte LanbideanBBK Fundazioa.

Polavieja, J. (2000): "Precariedad laboral y voto de castigo en España: en defensa de un modelo de interacción entre los condicionantes económicos e ideológicos del voto", Revista Española de Ciencias Políticas, 1(2), pp. 43-77.

Polavieja, J. (2003): Estables y precarios. Desregulación laboral y estratificación social en España, Madrid, CIS.

Prieto, C., ed. (2007): Trabajo, género y tiempo social, Madrid, Hacer/Complutense.

Rambach, A. y M. Rambach (2001): Les intellos précaires, París, Fayard.

Ramírez, E. (1996): Inmigrantes en España. Vidas y experiencias, Madrid, CIS/Siglo XXI.

Rodríguez Victoriano, J. M. (1999): "La sorpresa no era la emancipación adulta: autonomía virtual y dependencia real en la juventud española de la década de los noventa", Revista de Estudios de Juventud, 45, pp. 103-111.

Rojo Torcilla, E. (2002): "España 2002: el debate sobre la calidad y la precariedad del empleo", Sociedad y Utopía, 20, pp. 173-185.

Romainville, M. (2004): "L'apprentissage chez les étudiants", en Annoot, C. y M. F. Fave-Bonnet (eds.), Pratiques pédagogiques dans l'enseignement supérieur: enseigner, apprendre, París, L'Harmattan, pp. 130-141.

Salido, O. y A. Martín (2007): "Las urnas de la precariedad: el anclaje sociolaboral del voto juvenil en el 14-M", Sociedad y Utopia, 29, pp. 463-487.

San José Pérez, Ma L. (coord.), (2004): Conciliación de la vida laboral y familiar en la Comunidad de Madrid, Madrid, Agrupación de Madrid del Forum de Política Feminista. 
Sánchez Moreno, E. (2004): Jóvenes: la nueva precariedad laboral: la experiencia de la precariedad laboral en los jóvenes españoles, Madrid, Secretaría Confederal de Juventud de Comisiones Obreras.

Sánchez Moreno, E. y A. Barrón (2007): "Social Risk Factors in Spanish Youth and their Impact on Self-Concept Construction”, Spanish Journal of Psychology, 10 (2), pp. 328-337.

Santamaría, E. (2011): Trayectorias laborales en los márgenes del empleo: políticas, subjetividades y experiencias de jóvenes en la precariedad laboral, Vitoria-Gasteiz, Servicio Central de Publicaciones del Gobierno Vasco.

Santos Ortega, A. (2003): “Jóvenes de larga duración: biografías laborales de los jóvenes españoles en la era de la flexibilidad informal", Revista Española de Sociología, 3, pp. 87-98.

Solé, C. (1995): Discriminación racial en el mercado de trabajo, Madrid, CES.

Standing, G. (2011): The precariat. The New Dangerous Class, London, Bloomsbury.

Tejerina, B. (2010): "The logic of the Alterglobal Movement", en D.K. SinghaRoy (ed.) Dissenting Voices and Transformative Actions. Social Movements in a Globalizing World, New Delhi, Manohar, pp. 41-67.

Tejerina, B. (2011): “Condiciones de vida”, en A. Ariño y R. Llopis (dirs.), ¿Universidad sin clases? Condiciones de vida de los estudiantes universitarios en España (Eurostudent IV), Madrid, Ministerio de Educación, pp. 141-166.

Tejerina, B., B. Cavia, E. Santamaría y D. Carbajo (2012): Precariedad vital y juventud vasca. Condiciones sociales y estrategias biográficas para llevar una vida normal, Vitoria-Gasteiz, Servicio Central de Publicaciones del Gobierno Vasco.

Tejerina, B., B. Cavia, S. Fortino y J. A. Calderón (2013): Crisis y precariedad vital. Trabajo, prácticas sociales y modos de vida en Francia y España, Valencia, Tirant Lo Blanch.

Tezanos, J. F. (2001): La sociedad dividida. Estructuras de clases y desigualdades en las sociedades tecnológicas, Madrid, Biblioteca Nueva.

Tobío, C. (2005): Madres que trabajan. Dilemas y estrategias, Madrid, Cátedra.

Trow, M. (1972): The expansion and transformation of higher education, New Jersey, General Learning Press.

VV. AA. (2003): Tiempos, trabajos y flexibilidad: una cuestión de género, Madrid, Instituto de la Mujer, Ministerio de Trabajo y Asuntos Sociales.

Zubero, I. (2006): "Las nuevas relaciones entre empleo e inclusión: flexibilización del trabajo y precarización vital", Documentación Social, 143, pp. 11-30. 